\title{
Chemosensitization as a means to augment commercial antifungal agents
}

\section{Bruce C. Campbell *, Kathleen L. Chan and Jong H. Kim}

Plant Mycotoxin Research Unit, Western Regional Research Center, Agricultural Research Service, United States Department of Agriculture, Albany, CA, USA

\section{Edited by:}

Julianne Teresa Djordjevic, University of Sydney, Australia

\section{Reviewed by:}

Peter R. Williamson, National Institutes of Health, USA

Ameeta Agarwal, University of

Mississippi, USA

Sharon Chen, Westmead Hospital,

Australia

\section{*Correspondence:}

Bruce C. Campbell, Plant Mycotoxin Research Unit, Western Regional Research Center, Agricultural Research Service, United States Department of Agriculture, 800 Buchanan Street, Albany, CA 94710 , USA.

e-mail: bruce.campbell@ars.usda.gov
Antimycotic chemosensitization and its mode of action are of growing interest. Currently, use of antifungal agents in agriculture and medicine has a number of obstacles. Foremost of these is development of resistance or cross-resistance to one or more antifungal agents. The generally high expense and negative impact, or side effects, associated with antifungal agents are two further issues of concern. Collectively, these problems are exacerbated by efforts to control resistant strains, which can evolve into a treadmill of higher dosages for longer periods. This cycle in turn, inflates cost of treatment, dramatically. A further problem is stagnation in development of new and effective antifungal agents, especially for treatment of human mycoses. Efforts to overcome some of these issues have involved using combinations of available antimycotics (e.g., combination therapy for invasive mycoses). However, this approach has had inconsistent success and is often associated with a marked increase in negative side effects. Chemosensitization by natural compounds to increase effectiveness of commercial antimycotics is a somewhat new approach to dealing with the aforementioned problems. The potential for safe natural products to improve antifungal activity has been observed for over three decades. Chemosensitizing agents possess antifungal activity, but at insufficient levels to serve as antimycotics, alone. Their main function is to disrupt fungal stress response, destabilize the structural integrity of cellular and vacuolar membranes or stimulate production of reactive oxygen species, augmenting oxidative stress and apoptosis. Use of safe chemosensitizing agents has potential benefit to both agriculture and medicine. When co-applied with a commercial antifungal agent, an additive or synergistic interaction may occur, augmenting antifungal efficacy. This augmentation, in turn, lowers effective dosages, costs, negative side effects and, in some cases, countermands resistance.

Keywords: mycoses, azoles, natural products, antimycotic resistance, MAPK, cell wall/membrane integrity

\section{INTRODUCTION}

The term "chemosensitization" was originally introduced as a strategy to counter the development of resistance in tumor cells to anticancer chemotherapeutic agents. Simply put, chemosensitization in cancer therapy involves use of a chemical that renders cancer cells more sensitive to a chemotherapeutic agent. Development of resistance in cancer cells to anticancer drugs involved mutations in target genes, up-regulation or over-expression of genes controlling efflux pumps, production of enzymes that "detoxified" the drugs, and DNA repair (Shabbits et al., 2003). Employment of a chemosensitizer results in lowering dosages of cytotoxic anticancer drugs, overcoming chemo-resistance by cancer cells to these drugs, avoiding toxicity to non-target cells and lowering the extreme negative side effects to the patient associated with anticancer drugs.

The mechanisms of resistance to anticancer chemotherapeutic agents are almost completely parallel to those developed by fungal pathogens against antifungal agents. As in the advancement for cancer treatment, chemosensitizers may be especially useful for improving antimycotic chemotherapy against human mycoses or strategies to control plant fungal pathogens. Use of chemosensitizers could facilitate overcoming resistance to currently available antimycotics, without increasing risks of negative side effects. Such chemosensitizers could function by debilitating, or stressing the fungus so that it becomes more vulnerable to commercial agents. A fundamental characteristic of a chemosensitizer, however, is that while it contributes to augmenting the efficacy of drug activity, whether for treatment of cancer or mycoses, it does not present, or only minimally presents, additional toxic side effects.

Chemosensitizing agents, alone, may have some nominal antifungal activity, but most often an order of magnitude less than that of commercial antimycotics; which generally function at the micromolar level, or less. The chemosensitizing agents, on the other hand, function mainly as synergists that affect the target pathogen in such a way that it becomes more vulnerable (chemosensitized) to the commercial antimycotic agent. With chemosensitization, effective dosage levels of the commercial product can be significantly lowered, perhaps 10 -fold or more. Additionally, chemosensitization may cause strains that are resistant to an antimycotic to revert to becoming susceptible, or at least more sensitive to treatment.

There are laboratories, worldwide, performing research on chemosensitizing agents to boost antifungal activity. Yet, there 
has been a general unawareness of each other's activities. This was, and still is evident, by the fact that many of the publications on chemosensitization of antimycotics have not been citing each other's papers in the field. We include ourselves in this oversight. Recent reviews on synergism of antibiotics by natural products mainly entailed antibacterial research (Hemaiswarya et al., 2008; Wagner and Ulrich-Merzenich, 2009). These reviews did cite eight papers, however, on synergism of antimycotics, specifically. There are now well over 70 papers on chemosensitization of antimycotics cited in this review. Many of these papers have been published only within the past few years. Interest in this strategy is growing immensely as genetic tools have facilitated the discovery of stress response networks to serve as targets to weaken fungal defenses, whether structural or biochemical.

This review begins with an encapsulated overview of fungal diseases and development of antimycotic agents. Then, a picture of the emerging problem of resistance is presented as it applies to current-day circumstances into which chemosensitization may play a role for fungal control. The subject of chemosensitization, itself, is presented in-depth in the Section "Chemosensitization of Antifungal Agents." Therein, research on various facets of chemosensitization, including the chemical nature of the agents, their interaction with various commercial products, and their mode of action or how they sensitize a fungal pathogen, if known, is comprehensively covered. As fungal diseases confront both agriculture and medicine, this review will address fungal control and use of chemosensitizing agents against fungal pathogens in both fields. However, most of the research on chemosensitization has involved antifungal agents against human mycoses; which will, thus, be featured.

\section{FUNGAL DISEASES AGRICULTURAL FUNGAL DISEASES}

For centuries, successful treatment of fungal diseases of crops, animals, and humans was relatively intermittent. Fungal diseases of crops have had historic impacts on human civilization. Notable examples include the relatively recent Great Potato Famine of Ireland and Great Bengal Famine (rice) during the mid nineteenth and twentieth centuries, respectively. These famines each resulted in millions of human deaths. Moreover, $70 \%$ of all major crop diseases, to this day, are due to fungi. The long list of phytopathogenic fungi and related crop diseases, numbering in the 100s, is beyond the scope of this review. Overviews on crop fungal pathogens and fungicides employed are available (Levetin and McMahon, 2003; Russell, 2005; Strange and Scott, 2005). However, special mention should be given to the current crop fungal disease threatening the World. This is the fungal strain Ug99 (TTSK) of Puccinia graminis tritici, the fungus that causes wheat stem rust. Ug99 has the potential of infecting $90 \%$ of the World's wheat varieties. It has already had devastating effect on the wheat crop of East Africa and has spread to Asia and the Middle East (Singh et al., 2011).

\section{FUNGAL DISEASES OF MEDICAL IMPORTANCE}

The impact of human mycoses has not had the same level of historical infamy as those affecting crops, until recently. Fatal cases of thrush, later identified as being caused by the yeast Candida albicans from the patient's own microflora, had been known for centuries (Martin and Jones, 1940). However, it has only been within the last two decades that a sense of urgency developed in combating human mycoses. This urgency stems from a vast increase in incidence of opportunistic invasive fungal infections (IFIs). Major IFIs include disseminated candidiasis, cryptococcal meningitis, and invasive aspergillosis. The increase in incidence of these diseases had its inception in the early 1990s as a result of prodigious growth in the number of immunocompromised individuals, mainly arising from the AIDS epidemic, in addition to an increase in immunosuppressive treatments required for organ transplants, and an overall general debilitation (e.g., cancer malignancies) associated with an aging population (Low and Rotstein, 2011). The increased incidence of IFIs has required massive levels of antimicrobial chemotherapy accompanied by the overarching problem in the progressive emergence of resistance to available antimycotic agents (Loeffler and Stevens, 2003). This resistance has set off a vicious cycle of intensive antimicrobial chemotherapy, emergence of more resistant strains; which, in turn, promotes emergence of more therapeutically intractable IFIs (Tseng and Perfect, 2011; refs. therein). Compounding this problem is the sluggish pace at which new antimycotics are being discovered that have therapeutic practicality (Messer et al., 2009).

\section{FUNGICIDES AND ANTIMYCOTICS}

Following is a brief overview on the history in development of antifungal agents for use in agriculture and medicine. Included is an introduction to antifungal agents used and oversight committees that monitor emergence of resistant strains and which also provide advice on their control or treatment.

\section{AGRICULTURAL FUNGICIDES}

Development and use of commercial antifungal agents in agriculture predated that for human medicine. One of the main concerns in development of plant fungicides was phytotoxicity, characteristic to many early fungicides. The earliest fungicides used saltwater or lime to control wheat bunt in the seventeenth century. About a century later copper sulfate, then known as the Bordeaux mixture, was used to control powdery mildew of grapes. Most early fungicides were based on inorganic minerals, including arsenic and mercury. These had to be applied frequently and in large amounts to be effective, presenting obvious hazards to both human health and to the environment. In the early 1940s, new classes of fungicides, the dithiocarbamates and phthalides, were vast improvements over their prior inorganic counterparts. These newer fungicides had higher fungicidal activity, were easily formulated for application, and were less phytotoxic (Horsfall, 1975).

The modern panoply of agricultural fungicides began to be developed in the 1970s. The main ones included the ergosterol biosynthetic inhibitors benzimidazoles, morpholines, piperazines, imidazoles, pyrimidines, and triazoles; the mitochondrial respiration inhibitors, the anilides and strobilurins (Krämer and Schirmer, 2008; refs. therein) and osmoregulation disruptors, the phenylpyrroles (Kanetis et al., 2008).

In contrast to human patients, crops have an advantage in that they can be genetically modified for resistance against fungal diseases (Cornelissen and Melchers, 1993). But, as with fungicides, 
fungal pathogens eventually can produce resistant strains, as poignantly demonstrated, recently, with the Ug99 pandemic of wheat (Singh et al., 2008).

\section{ANTIMYCOTIC CHEMOTHERAPY}

Development of antimycotics against human mycoses lagged behind that for agricultural fungicides and even to that of antibiotics targeting bacteria. This delay was borne by the fact that, unlike bacteria, fungi are eukaryotes and have a closer evolutionary affiliation to humans. As such, they possess biochemical, genetic, and cellular biological traits more common to humans than do bacteria. Hence, finding suitable targets for fungal control that did not present a risk to the human host has been a more complicated endeavor than that for antibacterial agents.

It was not until the 1950s that the first fungus-specific antimicrobials were discovered, some two decades after the discovery of penicillin. These first antimycotics included griseofulvin and nystatin (Odds, 2003a). Griseofulvin, a polyketide isolated from Penicillium griseofulvum, has limited application and is mainly used against dermatophytosis. Its mode of action is by disrupting mitotic spindle microtubules in fungi, preventing cellular division (Panda et al., 2005).

The vast majority of antimycotic drugs discovered since griseofulvin disrupt fungal cell membrane integrity, in one way or another. The first of these to be discovered was nystatin, a polyene antimycotic isolated from a Streptomyces bacterium. Nystatin forms hydrogen bonds with ergosterol, a fungus-specific sterol, creating pores in the plasma membrane with concomitant cellular leakage (Cass et al., 1970). Nystatin has a broader range of antifungal activity than griseofulvin, but because of its nephrotoxicity it is limited to topical or oral administration, for treatment of dermatophytic and oropharyngeal infections.

Within a few years another antimycotic polyene was isolated from Streptomyces nodosus, amphotericin B (AMB), having much greater antifungal activity than nystatin, which is a mainstay of antifungal chemotherapy to this day. Like nystatin, AMB binds to ergosterol (Dutcher, 1968). However, it can, to a much lesser degree, bind to other sterols, such as cholesterol, a component of mammalian cell membranes, and its use has been associated with significant side effects, including kidney failure and death. New formulations of AMB as a lipid or a cholesteryl sulfate complex or in liposomal form (L-AMB) have been successful in reducing these side effects and improving patient tolerance to this drug (Thompson et al., 2009). AMB was the primary drug used against IFIs until the advent of the triazoles (Walsh et al., 2008).

The azoles were the next class of clinically acceptable antifungal agents, first appearing in 1969. The primary mode of action of all azoles is prevention of ergosterol biosynthesis. Azoles inhibit a fungal enzyme, $14 \alpha$-sterol demethylase (cytochrome $\mathrm{P} 450_{\mathrm{DM}}$ ), that is required for demethylation of lanosterol to ergosterol (Maertens, 2004). The imidazoles (e. g., miconazole, bifonazole, clotrimazole, ketoconazole, etc.), were the first azoles to be used, mainly in topical ointments. Oral or systemic use of imidazoles was unacceptable in view of hepatotoxicity and erratic effectiveness. Although ketoconazole was eventually approved for systemic use in 1981, it is not effective against deep-seated mycoses.
Shortcomings of imidazole agents for systemic mycoses led to discovery of a second group of azoles, the triazoles. However, triazoles have a greater affinity for $14 \alpha$-sterol demethylase enzyme than do the imidazoles. An additional contributing factor to the antifungal effect of the triazoles is aggravation of oxidative stress in the fungus through greater accumulation of methyl sterols. Accumulation of these sterols sensitizes fungal cells to the oxidative burst from phagocytic cells (Shimokawa and Nakayama, 1992).

However, toxicity of triazoles to the patient can result from cross-reactivity with several human cytochrome P450-dependent enzymes (Thompson et al., 2009). There is a long list of other drugs posing a risk of exacerbating negative interactions, if coadministered with triazoles. The current clinically approved triazoles include itraconazole, the first of this class approved for clinical use, followed by fluconazole (FLU), perhaps the most widely used, and three "second generation" triazoles, voriconazole, posaconazole, and ravuconazole (Odds, 2003a).

The most recent class of commercially available systemic antifungal agents is the echinocandins. This class of antimycotics inhibits synthesis of $\beta$-1,3-glucan, an essential constituent of the fungal cell wall and not found in humans. Lack of this polysaccharide undermines cell wall integrity rendering the cell vulnerable to osmotic stress and cell lysis. The first echinocandin approved for clinical use was caspofungin, discovered in 2000 (Onishi et al., 2000). Additional echinocandins approved for therapeutic use include micafungin and anidulafungin. This class of antimycotics has reportedly fewer side effects than the polyenes and azoles, and are considered to be well tolerated by patients. While showing efficacy against Candida spp. and Aspergillus spp., the echinocandins have low efficacy against cryptococci (Eschenauer et al., 2007).

\section{RESISTANCE}

Development of resistance to currently available, commercial antifungal agents is, perhaps, the major problem confronting their use in both agriculture and medicine. A second common issue is the inherent toxicity that antifungal agents present to human health, and other non-target organisms in the environment. Of particular concern is the possibility that fungicides applied in the environment for control of agricultural fungal pathogens may contribute to development of cross-resistance by human infectious fungi. This may especially be the case with triazoles, a class of antifungal agents used both in agriculture and in medicine (Snelders et al., 2009).

Despite success in discovery of new therapeutic antimycotics, development of resistance remains the main clinical problem in treatment of IFIs. Resistant strains of yeast and filamentous IFI agents have been found for all major classes of antimycotics, including the most recent echinocandins, with their novel mode of action. As a result, clinical failures in antimycotic chemotherapy are an increasingly vexing and worrisome problem.

Chemosensitization has the potential to fundamentally augment efficacy of antifungal agents. But, perhaps its greatest promise is in subverting resistance. In order to understand this capability, a brief overview is provided on the mechanisms of resistance and how significant of a concern resistance has become for the control of both agricultural and medical pathogenic fungi. 


\section{RESISTANCE TO AGRICULTURAL FUNGICIDES}

Currently, there are over 150 different agricultural fungicides in use, worldwide (Phillips McDougall, 2006). Development of widespread fungicide resistance in crop pathogens has been a continuous, fundamental problem, especially over the past 35 years. Recognition of this problem reached such significance that an international consortium of fungicide manufacturers, academic, and government scientists and crop advisors, was organized in 1994 as the Fungicide Resistance Action Committee (FRAC). Publication of an overview of fungicide resistance in crop systems, worldwide, shortly followed (Brent, 1995). FRAC has since published a number of monographs, the latest update published in 2007 (Brent and Hollomon, 2007). Fungicide resistance management has become a mainstay in pre- and post-harvest agriculture (Förster et al., 2007).

Today, resistant strains of crop fungal pathogens can be found for just about all classes of agricultural fungicides. The type of resistance and the degree to which it has spread greatly depends on several factors including mode of action, exclusivity of usage, geographic expanse of application, single gene-target, reproductive rate of the pathogen, and cross-resistance within the class of fungicide. The potential interaction of these factors in promoting resistance requires a vigilance and communication; which is generally coalesced into an "action" compendium by FRAC. FRAC has classified the major fungicides into various risk categories with the benzimidazoles, dicarboximides, phenylamides and the strobilurins, a fairly new class of fungicides, relegated to the "highrisk" category (Morton and Staub, 2008). Cross-resistance between fungicides may now extend into development of resistance in fungi of medical importance from exposure to agricultural triazoles (Deising et al., 2008; Snelders et al., 2009).

A prevalent mechanism by which fungi develop resistance is called altered target site or qualitative resistance. This can be a single point mutation in one amino acid in a fungal target protein. Generally, this type of resistance renders the fungus fundamentally resistant, reflected by ineffectiveness no matter the rate of application of the fungicide. Qualitative resistance has played a significant role in limiting efficacy of fungicides targeting various components of mitochondrial respiratory complexes, known as quinone outside inhibitors ( $\mathrm{QO} I \mathrm{~s}$ ), such as the strobilurins. Resistance to QoIs may have developed rapidly because their target proteins are encoded on mitochondrial DNA, and, thus, may not have the DNA repair capability equal to that found in nuclear DNA (Gisi et al., 2002). Other types of resistance include increased efflux transporter activity, altered membrane structure reducing fungicide absorption, fungicide degradation or over-expression of the target gene (Del Sorbo et al., 2000). These latter mechanisms can be possibly overcome by increased fungicide application rates, and are referred to as quantitative resistance (Deising et al., 2008).

\section{RESISTANCE TO CHEMOTHERAPEUTIC ANTIMYCOTICS}

The rapid development of resistance to clinical antimycotics is a worrisome predicament for effective treatment of IFIs (Nucci and Perfect, 2008). There have already been over a half million deaths from cryptococcosis in sub-Saharan Africa, alone, with an estimated $>600,000$ deaths per year from cryptococcal meningitis, worldwide (Park et al., 2009). Of the polyene, triazole, or echinocandin drugs available, development of resistant strains to at least any one of these drugs has resulted in clinical failures in cryptococcosis, candidiasis or aspergillosis (Tseng and Perfect, 2011). Resistance to these drugs may reflect the dearth of targets, such as ergosterol-binding or inhibition of singular enzymes involved in ergosterol or $\beta$-1,3-glucan biosynthesis, respectively. With the current set of clinical antimycotics the overall target involves membrane/cell wall integrity. Another class, represented by flucytosine, disrupts transcription/translation processes in fungal cells by interrupting uracil production (Vermes et al., 2000). However, because of the propensity for rapid development of resistance against flucytosine, when used alone, it is often combined with other antimycotics, such as AMB against cryptococcal meningitis (Hope et al., 2004; Papon et al., 2007).

The mechanisms of resistance of human and crop fungal pathogens are similar. Antifungal drug resistance is divided into two categories, "microbiological" and "clinical" (Kanafani and Perfect, 2008). Microbiological resistance is when a strain is not susceptible to a dosage above an established breakpoint level, based on standardized laboratory protocols, e.g., CLSI (2008a) and is divided into categories, "primary" and "secondary." These categories are analogous to "quantitative" and "qualitative" used to describe resistance in crop fungal pathogens. In primary resistance, the pathogen is innately resistant without any prior exposure to the drug. An example is resistance of Cryptococcus neoformans to echinocandins. In contrast, secondary resistance develops after repeated exposure to a drug, creating selection-pressure for genetic changes in the pathogen, such as up-regulation of efflux pumps (Niimi et al., 2004; Cannon et al., 2009), site mutations in target genes, gene duplication, etc. Secondary resistance can be found extensively among clinical strains and species of Candida. Examples include FLU resistance owing to enhanced expression of genes coding efflux pumps (CDR1 and CDR2), or lanosterol demethylation to ergosterol (ERG11; Shen et al., 2010) or resistance to echinocandins by mutation in the $\beta$-1,3-glucan biosynthetic gene FKS1 (Ben-Ami et al., 2011). In some cases, mechanisms of drug resistance can involve multiple genes, as in certain strains of $A$. fumigatus showing pan-resistance to azoles (Camps et al., 2012).

Clinical resistance basically entails cases where in vitro assays fail to match in vivo results. This occurs when there is a discrepancy between laboratory determinations predicting drug efficacy, based on minimum inhibitory concentrations (MICs) according to standardized protocols (e.g., CLSI, 2008a) and failure of drug treatment under clinical conditions. The factors involved in clinical resistance are responsible for the majority of drug failures in IFI therapy (Anderson, 2005; Kanafani and Perfect, 2008). These factors may entail misdiagnosis, drug pharmacokinetics, host/pathogen interactions, the infection site, fungal burden, interactions with other infecting agents, immunocompetence, etc.

\section{REMEDIATION STRATEGIES: MANAGING RESISTANCE TO ANTIFUNGAL AGENTS}

There are similarities in strategies in agricultural and medicine to circumvent emerging resistance to antifungal agents. However, there are also some vast differences, mainly a result of constraints placed on the latitude in risking human health; although environmental risks associated with fungicidal usage are a concern. In fact, 
the original inorganic agricultural fungicides (copper and sulfur based) are still used. However, overcoming antifungal resistance by chemosensitizing agents could benefit both agriculture and medicine, discussed further in the Section "Chemosensitization of Antifungal Agents.”

\section{Managing resistance to agricultural fungicides}

Management strategies and guidelines employed for resistance to agricultural fungicides are evaluated regularly and published in monograph form under the aegis of FRAC (Brent and Hollomon, 2007). Successful management of resistance in crop fungal pathogens generally necessitates large-scale cooperation over broad areas; which requires agreement and commitment by both fungicide manufacturers and farmers. Strategies include the following: (1) Combine application of and diversify fungicides (this is analogous to combination therapy in clinical practice, see below), or rotate use, so that more than one target in the fungus is being affected; (2) Restrict application to critical periods to reduce selection-pressure for developing resistance; (3) Do not exceed recommended rates; (4) If the resistant fungal pathogen is already well established, avoid applying to eradicate, but use prophylactic levels to keep populations low; (5) Withdraw ineffective fungicides from the market; and (6) Develop new fungicides. It is this latter factor that agriculture has an advantage over that of medicine in ameliorating fungicide resistance. The multitude of available fungicide classes, and actual number of agricultural/horticultural fungicides, eclipse the number of drugs available for human antimycotic chemotherapy. Thus, there is a greater probability for maintaining and improving the efficacy of fungicides used for agriculture, through altering chemical structure, without the limitations of causing serious side effects, as in the medical arena. Moreover, in agriculture, the fungal pathogen only need be "controlled" during crop growth or storage, and not completely "eradicated," as is generally required in cases of human mycoses.

\section{Managing resistance to antimycotic drugs}

Managing antimycotic resistance involves a number of factors. These include improving hospital sanitation (Benet et al., 2007), surveillance for resistance, changing antimycotic, combination therapy and development of new antimycotic drugs or therapeutic strategies (e.g., chemosensitization).

Vigilance with regard to emerging resistance in both filamentous fungi and Yeast is, today, performed by either of two standardized laboratory protocols for determining respective MICs, as proposed by CLSI (2008a,b) and the European Committee on Antimicrobial Susceptibility Testing (EUCAST, 2008a,b). A recent side-by-side comparison of each committee's respective assay methods for MICs of selected triazoles for strains and species of Candida (>1000 clinical isolates) and for Aspergillus (245 clinical isolates) found $>97 \%$ (Pfaller et al., 2011c) and $>98 \%$ (Pfaller et al., 2011a) concordance between the two protocols, respectively.

Surveys of global clinical collections to detect potentially resistant strains and species can provide insights on how to approach antimycotic chemotherapy in a given global region. This approach is currently performed by the ARTEMIS Antifungal Surveillance Program (see Pfaller et al., 2005). Such global surveys provide useful information with regard to potential efficacy of antimycotic drugs. A recent example is where MICs were determined for the azoles, FLU, voriconazole and posaconazole for almost 1000 strains from a global collection of C. neoformans (Pfaller et al., 2011b). This survey provided a means of detecting emerging resistance in several global regions. Establishment of clinical susceptibility breakpoints provides reasonable predictors of failure of any particular antimycotic. In this study, no clinical breakpoints had been established for any of these drugs against C. neoformans, yet the survey provided epidemiologic cut-off values for each of the drugs based on strains having MICs departing greatly from overall modal MICs of wild-type strains. For example, the overall modal MIC of FLU against C. neoformans, in worldwide surveys, is $4 \mu \mathrm{g} \mathrm{mL}^{-1}$. Whereas, MICs $>64 \mu \mathrm{g} \mathrm{mL}^{-1}$ of strains in Southeast Asia and Africa (Chandenier et al., 2004; Bicanic et al., 2007) reflected clinical failures using FLU.

Combination therapy involves use of two or more antimycotics, concurrently or sequentially (Baddley and Pappas, 2005). Such an approach may be effective in two ways. One is through synergistic interaction, where antifungal efficacy is increased when drugs are combined. The other is impeding development of resistance because multiple genetic targets in the fungus are being overwhelmed. However, the practicality of combination therapy has had mixed results. Laboratory assays (in vitro) have shown positive or synergistic interactions between combinations of many commercial antimycotics (Cuenca-Estrella, 2004; Chaturvedi et al., 2011). Combinations of all three representatives of the "modern" classes of systemic antimycotics, AMB, voriconazole and caspofungin, showed highly synergistic antifungal activity, in vitro, against aspergillosis agents, $A$. fumigatus, $A$. terreus and A. flavus. However, the interaction became antagonistic at higher concentrations of AMB or voriconazole (O'Shaughnessy et al., 2006). Another example is where combinations of azole and one or two of the caspofungin antimycotics are synergistic, in vitro, against clinical strains of Candida and Cryptococcus (Roling et al., 2002). However, when administered clinically (in vivo), the benefits of combination therapy may not always be realized as there may not be greater antimycotic efficacy and there may be a worsening of negative side effects (Steinbach et al., 2011).

New antifungal agents, beyond the more recently available azoles and echinocandins, are desperately needed as there is emerging resistance and some strains showing innate refractoriness to all of them. Optimally, such new agents should target different systems within the fungus than those being targeted currently. Such new targets could include the calcineurin pathway, $\beta-1,6-$ glucan biosynthesis, mitochondrial respiration, biofilm formation or genes specifically controlling fungal physiological events, such as spore formation, filamentation, etc. (Espinel-Ingroff, 2009).

However, it is within the concept of "combination therapy" or "new antifungal agents" that chemosensitization may have its greatest utility. The remainder of this review is devoted to the research on safe, chemosensitizing agents that could improve antifungal chemotherapy (medicine) or phytopathogenic fungal control (agriculture).

\section{CHEMOSENSITIZATION OF ANTIFUNGAL AGENTS}

A growing number of papers have begun to appear over the past decade showing that certain natural products, relatively non-toxic 
to humans, increase antifungal activity when co-administered with a commercial antifungal agent. Many of these products ("chemosensitizers") are known constituents of commonly used herbs and spices. Because these herbs and spices have been part of the human culinary regimen for centuries, there is a presumption that the constituents of these plants are probably relatively safe. Moreover, various synthetic products have been identified having a synergistic interaction with commercial antimycotics, while not possessing significant antifungal activity alone. The mode of action of these natural and synthetic chemosensitizers to increase antimycotic activity is not always understood. However, research is beginning to show that many of these compounds interfere with the ability of fungi to respond to stress. Such stress may be from an environmental source (e.g., uv, heat, drought, etc.) or from a commercial antifungal agent. Other modes of action of chemosensitizers include disruption of fungal membrane integrity, inhibition of efflux pumps, or induction of oxidative stress. A comprehensive listing of research papers on chemosensitization of antifungal agents, types of compounds tested and modes of action, if known, is available in Table $\mathbf{1 .}$

Interactions between antifungal compounds are usually first determined, in vitro, by microdilution checkerboard assays either using CLSI (2008a,b) or EUCAST (2008a,b) protocols. Synergistic, additive or antagonistic interactions are defined by comparing the lowest concentration of agent needed to inhibit fungal growth, MICs, after test agents are combined, to MICs of the agents, alone. These interactions are recorded as Fractional Inhibitory Concentration Indices (FICI), where: $\mathrm{FICI}=\mathrm{MIC}$ of compound $\mathrm{A}$ in combination with compound $\mathrm{B} / \mathrm{MIC}$ of compound $\mathrm{A}$, alone $)+($ MIC of compound $\mathrm{B}$ in combination with compound $\mathrm{A} / \mathrm{MIC}$ of compound $\mathrm{B}$, alone). Compound interactions are defined as follows: synergistic (FICI $\leq 0.5$ ), additive $(0.5<\mathrm{FICI} \leq 1)$, neutral $(1<\mathrm{FICI} \leq 2)$ or antagonistic $(\mathrm{FICI}>2$; Isenberg, 1992), or the more guarded interpretation of FICI values of $\leq 0.5$ as synergy, and $>0.5-4$ as indifference (Odds, 2003b). Interactions can also be calculated according to fungicidal activity as Minimum Fungicidal Concentration (MFC) as the lowest concentration of agent where $\geq 99.9 \%$ fungal death is achieved and fractional fungicidal interaction indices (FFCIs) are calculated as for FICIs.

\section{CHEMOSENSITIZATION OF AGRICULTURAL FUNGICIDES}

Compared to the amount of research on chemosensitization of antifungal drugs, there has been relatively little research on their use with agricultural fungicides. This is quite in contrast to that of the research on discovery of natural fungicides, of which there are many. However, the source of almost all of the widely used commercial fungicides for agriculture is mainly bacterial, particularly species of Streptomyces (Copping and Duke, 2007). Such fungicides include the polyoxins, kasugamycin, and more. The strobilurins, already discussed, are natural products from the fungus, Strobilurus tenacellus. While these compounds have potent antifungal activity they also possess high mammalian toxicity.

Plant natural products have also been used for controlling plant fungal pathogens. However, these compounds, in general, do not exhibit antifungal activities sufficient for wide commercial acceptance. Moreover, many of these plant-derived compounds are phytotoxic and, thus, are of limited utility in crop systems other than, perhaps, as promising candidates as chemosensitizers for antimycotic drugs (see below). Few have been assessed as chemosensitizing agents to agricultural fungicides.

Cinnamaldehyde is perhaps the most widely known of plant natural products used as a fungicide against plant, or plantproduct fungal pathogens (Copping and Duke, 2007). Its mode of action was proposed to be similar to that of the echinocandins, in that it inhibited $\beta$-1,3-glucan synthase (Bang et al., 2000). Alone, cinnamaldehyde has only nominal antifungal activity. However, cinnamaldehyde in combination with other plant natural products, the phenolics eugenol, quercetin, and catechin, resulted, in some cases, in a $>100$-fold synergistic antifungal activity against wood-decaying fungi (Yen and Chang, 2008). It was concluded that the combination of fungal cell wall degradation, and the associated osmotic stress (cinnamaldehyde), with the addition of an oxidative stress agent (the phenolics) resulted in synergistic antifungal activity. Combination of cinnamaldehyde and another plant phenolic, octylgallate, also showed a promising level of antifungal activity against wood-decaying fungi (Hsu et al., 2007); the mode of action of octylgallate proposed to result from cell membrane surfactant properties (Kubo et al., 2001).

With regard to actual synergism of commercial fungicides, octylgallate was found to synergize antifungal activity of fludioxonil and a strobilurin, kresoxim-methyl, against the apple pathogen Penicillium expansum, in vitro. However, based on hypersensitivity of singular gene deletion mutants of Saccharomyces cerevisiae, as a model fungus, it was concluded that octylgallate disrupted the oxidative stress response system, debilitating the fungus further to the oxidative stress introduced by the fungicides (Kim et al., 2010b). In addition, the combination of octylgallate and fludioxonil rendered $P$. expansum fludioxonil-resistant strains to become susceptible.

Further research on chemosensitization of crop fungal pathogens to commercial fungicides has mainly involved $A$. flavus. A. flavus is not a plant pathogen, per se, but an opportunistic fungus, generally infecting a variety of crops or crop-products under some form of environmental stress (e.g., drought, heat, insect damage). The main concern of infections of crops by $A$. flavus is contamination by aflatoxin, a highly carcinogenic mycotoxin (Yu et al., 2007). In an effort to develop methods for controlling A. flavus, focus was placed on various natural products as chemosensitizing agents to commercial fungicides. One of the first efforts found that the phenolic, 2,5-dihydroxybenzoic acid, disrupted glutathione homeostasis, significantly enhancing, by almost 100-fold, the antifungal activity of fludioxonil (Kim et al., 2007b). Additional natural compounds were also found to enhance activity of commercial fungicides. These included the alkaloid, berberine, and several phenolic compounds, enhancing antifungal activity of fludioxonil and strobilurin against $A$. flavus by further disrupting its oxidative stress response system (Kim et al., 2007a). Also tested were 2,3-dihydroxybenzaldehyde, salicylaldehyde and other benzo analogs. These compounds enhanced activity of strobilurins and antimycin A against A. flavus and $P$. expansum by disrupting the HOG1 signaling pathway, which controls osmotic and oxidative stress responses in fungi (Kim et al., 2008b, 2011). 


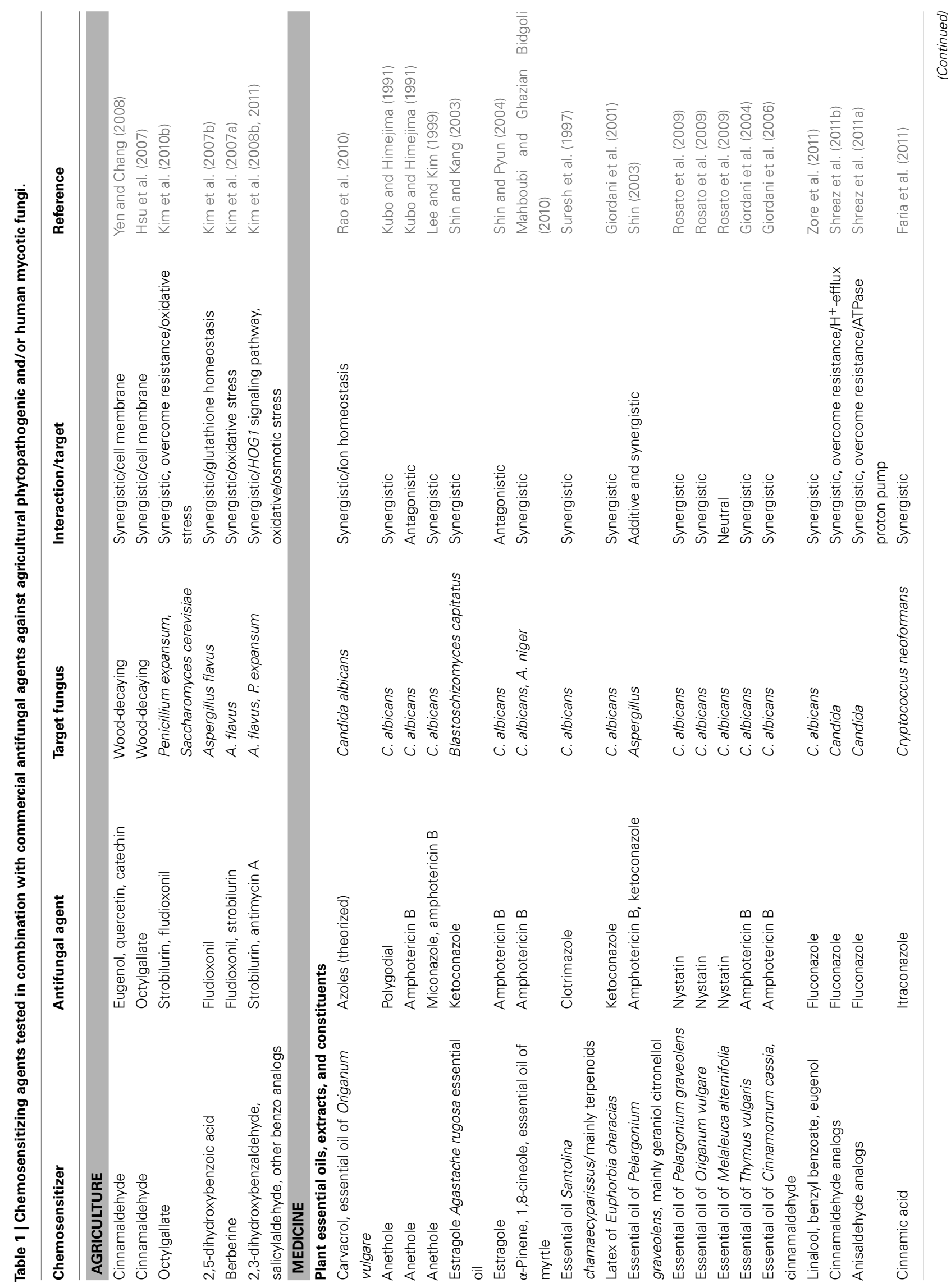








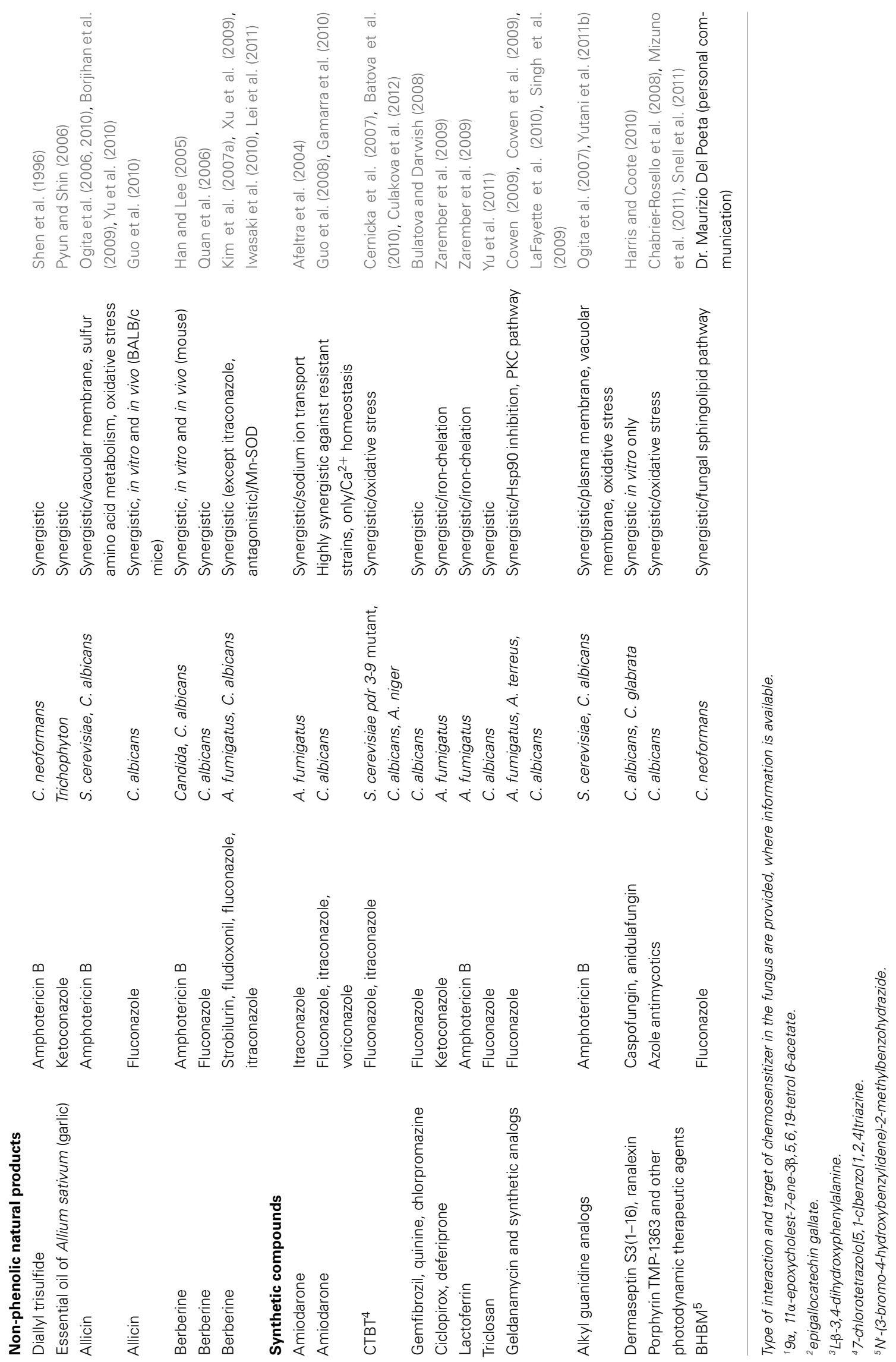
Interestingly, gallic and caffeic acids are potent inhibitors of aflatoxin biosynthesis (Mahoney and Molyneux, 2004; Kim et al., 2008c). Based on microarray analysis it was found that only a few genes of A. flavus were upregulated when treated with caffeic acid; the most prominent ones being peroxiredoxin genes. These genes encode enzymes that reduce endogenous peroxides, but also act in the signaling pathway of the oxidative stress response. Further studies on phenotypic responses of gene deletion mutants showed that antioxidants, such as gallic or caffeic acid, specifically target the antioxidative stress response system of $A$. flavus, shutting down the aflatoxin biosynthetic pathway (Kim et al., 2005, 2008c). Collectively, these results indicate that the chemosensitizing mode of action of redox-active phenolic compounds is associated with the fungal antioxidation system.

All of the aforementioned studies were conducted in vitro. Many compounds have been found to show some promise as chemosensitizers to commercial fungicides. However, so far, no field studies on use of these chemosensitizers co-applied with a commercial fungicide have been reported.

\section{CHEMOSENSITIZATION OF ANTIMYCOTIC DRUGS}

Use of natural fungicidal agents to treat human mycoses, especially dermatophytosis, is an ancient practice, notably in Chinese herbal medicine (Han et al., 2007). Natural products as chemosensitizers were first used as a means of "pharmacologic circumvention of multidrug resistance" using Vinca alkaloids as inhibitors of drug efflux pumps overexpressed in malignant cells resistant to anticancer drugs (Ford and Hait, 1993). It is, perhaps, for these two reasons there has been far more research on chemosensitization of antifungal drugs in human medicine, than with fungicides in agriculture. The higher level of chemosensitization research on antimycotic drugs may also result from the much more limited number of antifungal agents available, than that for agriculture. These factors, plus the additional problem of emerging resistance to antifungal drugs, have all spurred on an effort to investigate new approaches in antimycotic chemotherapy, especially with regard to phytopharmaceuticals (Wagner and Ulrich-Merzenich, 2009).

\section{Plant and marine natural products}

For centuries, crude infusions of leaves and flowers have been used in folk medicine to treat superficial cutaneous fungal infections, especially historic with regard to Chinese and Ayurvedic medicinal herbs. These infusions contain natural products of plant essential oils (Kalemba and Kunicka, 2003) and many of those found in spices, in particular, have been found to be antimycotic (Beuchat, 1994; Arora and Kaur, 1999). Moreover, plant natural products that show antimicrobial activity have some potential as therapeutic agents in combination or can serve as precursors for structural modification to augment activity (Wink, 2008).

Plant extracts and essential oils. In general, it has long been shown that the essential oils of "spices" have antifungal activity against cutaneous and systematic mycotic agents. One recent example shows that antifungal activity of the essential oil of Lavandula viridis, a member of the mint family, is due to its monoterpenes. The composite extract of this oil showed antifungal activity against various dermatophytes, C. albicans and C. neoformans by disrupting cell membrane integrity (Zuzarte et al., 2011).
Moreover, many of the individual compounds of these extracts, such as thymol, eugenol, and their $O$-methyl derivatives, possess nominal antifungal activity (Fontenelle et al., 2011). The steam distillate of Thymus pulegioides, also a member of the mint family, containing mainly carvacrol and thymol, had considerable antifungal activity against a variety of strains of dermatophytic fungi, Candida and Aspergillus. As with the steam distillate of L. viridis, this oil created lesions in the fungal cell membrane and reduced ergosterol content (Pinto et al., 2006). It has been proposed that antifungal activity of carvacrol followed a similar pattern as that for thymol, creation of cellular membrane lesions (Pinto et al., 2009). However, other modes of action have been proposed. Antifungal activity of carvacrol, thymol and eugenol were shown to be directly correlated to amplitude of $\mathrm{Ca}^{2+}$ bursts coupled with up-regulation of stress response pathways and drug efflux. Carvacrol triggers ionic disruption and cellular stress related to an inability to regulate vacuolar acidification. Such activity of carvacrol, and other phenolic compounds found in essential oils, may synergistically interact with azole drugs, also known to inhibit $\mathrm{H}^{+}$-efflux, affecting vacuolar acidification (Rao et al., 2010). The chemosensitizing mode of action of these types of compounds with commercial antimycotics is discussed further, below.

Combinations of plant essential oils and commercial antimycotics have resulted in synergistic antifungal activity. Combination of two plant terpenoids, anethole, a natural phenylpropene imparting flavor to anise and fennel, and polygodial had synergistic antifungal activity against $C$. albicans, at clinically practical MICs $\left(<0.1 \mu \mathrm{g} \mathrm{mL}^{-1}\right)$. But, combination of anethole and AMB were antagonistic, lowering antifungal activity (Kubo and Himejima, 1991). Anethole combined with both miconazole and AMB resulted in synergistic activity against C. albicans (Lee and Kim, 1999). Estragole, another phenylpropene and the main constituent of the essential oils of a Korean medicinal herb, Agastache rugosa, combined with ketoconazole also resulted in synergistic antifungal activity against Blastoschizomyces capitatus, a rare fungal pathogen often resulting in fatal mycoses in immunocompromised individuals (Shin and Kang, 2003). However, combination of estragole with $\mathrm{AMB}$ was antagonistic, reducing antifungal activity against $C$. albicans (Shin and Pyun, 2004). It was recently shown that anethole is an inhibitor of fungal chitin synthase (Yutani et al., 2011a). Hence, the antifungal synergism between the phenylpropenes and the azoles is probably related to effectively reducing overall fungal cell wall/membrane integrity. The mode of phenylpropene antagonism with AMB is unknown. Perhaps the phenylpropenes inhibit binding of polyene drugs to ergosterol. However, the essential oil of myrtle (Myrtus communis), consisting mainly of the monoterpenes $\alpha$-pinene and 1,8-cineole, has been shown to have synergistic activity with AMB (FICI 0.26) against strains of C. albicans and A. niger (Mahboubi and Ghazian Bidgoli, 2010). No mode of action for this synergism was provided.

One of the earliest investigations of the effects of combining plant essential oils and a clinical antimycotic involves a small medicinal herb, Santolina chamaecyparissus, cultivated in Europe, Asia and Africa. The essential oil from this plant was found to have a synergistic antifungal effect against C. albicans when combined with clotrimazole, in both in vitro and in vivo (murine) assays (Suresh et al., 1997). The essential oil of S. chamaecyparissus 
contains more than 80 constituents, practically all terpenoids, many common to a broad spectrum of plants (Grosso et al., 2009). Combination of the latex of Euphorbia characias, known to contain a high concentration of terpenes, with ketoconazole also resulted in synergistic antifungal activity against C. albicans in in vitro assays (Giordani et al., 2001). The essential oil of Pelargonium graveolens, used in the perfume industry, and its main components, geraniol and citronellol, had additive and synergistic in vitro antifungal activity against two species of Aspergillus, in combination with AMB or ketoconazole (Shin, 2003). Another in vitro examination of the essential oil of $P$. graveolens in combination with nystatin showed some synergistic activity against clinical strains and species of Candida, but not to the extent of the synergistic interaction of nystatin with the essential oil from Origanum vulgare (oregano; Rosato et al., 2009). Interestingly, this study did not find any synergism between nystatin and the essential oil of Melaleuca alternifolia, a common herbal antibacterial or antifungal preparation.

Of the herbs Satureja montana, L. angustifolia, L. hybrida, Syzygium aromaticum, O. vulgare, Rosmarinus officinalis and six chemotypes of T. vulgaris, the essential oil from one of the chemotypes of T. vulgaris lowered the MIC of AMB by $80 \%$ against $C$. albicans at $0.01-0.3 \mu \mathrm{g} \mathrm{mL}^{-1}$ (Giordani et al., 2004). However, at very low dosages of AMB $<0.0025 \mu \mathrm{g} \mathrm{mL}^{-1}$, the interaction was antagonistic. Combination of the essential oil from Cinnamomum cassia (Chinese cinnamon), containing mainly cinnamaldehyde, with $\mathrm{AMB}$ showed synergistic antifungal activity against C. albicans, reducing the MIC of AMB by $80 \%$ (Giordani et al., 2006). Six common terpenoids associated with essential oils of plants were highly synergistic with FLU against $C$. albicans with the FICIs of linalool (0.14), benzyl benzoate (0.156), and eugenol (0.265) indicating greatest chemosensitizing capacity (Zore et al., 2011). Three analogs of cinnamaldehyde were recently found to inhibit $\mathrm{H}^{+}$. efflux of FLU-resistant strains of Candida. Wherein, FLU inhibited $\mathrm{H}^{+}$-efflux in susceptible strains, it had little effect on this efflux in the resistant strains (Shreaz et al., 2011b). Inhibition of plasma membrane $\mathrm{H}^{+}$-ATPase activity, especially by the 3,5-dimethoxy4-hydroxycinnamaldehyde analog, occurred in conjunction with damage to the plasma membrane. Another group of benzenoids, analogs of anisaldehydes, showed almost identical results to those identified with the cinnamaldehydes, including activity relationships based on the position of methoxyl groups on the aromatic ring (Shreaz et al., 2011a). The acidic analog of cinnamaldehyde, cinnamic acid, was synergistic with itraconazole against $C$. neoformans (Faria et al., 2011). The effects of these benzenoid natural products on pathogenic yeasts, including FLU-resistant Candida, indicate such compounds may have a promising role in drug against candidiasis and cryptococcosis in conjunction with azole antimycotics.

Simple terpenoids. Natural plant compounds from essential oils that have been studied the most with regard to antimycotic chemosensitizing are eugenol, the predominant natural phenolic of clove oil, and thymol analogs. As observed for cinnamaldehyde (Shreaz et al., 2011b) and anisaldehyde (Shreaz et al., 2011a) benzenoids, the anticandidal mode of action of eugenol and thymol also involves inhibition of $\mathrm{H}^{+}$-ATPase driven efflux, leading to intracellular acidification (Ahmad et al., 2010b). Similar to the cinnamaldehydes, both these compounds disrupt the ultrastructure of the plasma membrane of Candida. Moreover, when combined, a synergistic anticandidal activity occurs (Braga et al., 2007). Of even more interest is the synergistic interaction between eugenol or methyleugenol with FLU, against clinical strains of FLU-resistant (MICs FLU $>64 \mu \mathrm{g} \mathrm{mL}^{-1}$ ) species of Candida. In vitro checkerboard assays of these compounds with Candida strains having FLU MICs $\geq 80 \mu \mathrm{g} \mathrm{mL}^{-1}$ resulted in FICIs $<0.5$ for almost all strains tested, with methyleugenol showing greater chemosensitizing potency than eugenol (Ahmad et al., 2010a).

One of the first papers studying the interaction between thymol and antimycotic drugs involved mitogen activated protein kinase (MAPK) mutants sakA $\Delta$ and $m p k C \Delta$ of $A$. fumigatus involved in osmotic/oxidative stress regulation. The sakA $\Delta$ was significantly more tolerant to certain experimental antifungal agents (Congo red and calcofluor white) than the wild-type and $m p k C \Delta$ mutant. The antifungal compounds tested targeted fungal cell membrane/cell wall integrity as determined by hypersensitivity of slt $2 \Delta$ and bck $1 \Delta$ mutants of $S$. cerevisiae, having deleted genes in the cell wall integrity MAP kinase pathway. Co-application of thymol with ketoconazole, FLU or AMB resulted in complete growth inhibition of the A. fumigatus wild-type strain at lower doses compared to independent treatment of each compound (Kim et al., 2008a). However, a later study that included additional strains of $A$. flavus and A. terreus showed mixed results. Combinations of thymol with ketoconazole, FLU or AMB resulted in enhanced antifungal activity, as above, with all strains except two of $A$ terreus, where the interaction was antagonistic (Kim et al., 2010a). The cause of this antagonism has yet to be determined. Thymol was also found to have synergistic interaction with FLU against FLU-resistant clinical strains of $C$. albicans according to FICIs in in vitro checkerboard assays (Guo et al., 2009). Another study found thymol to have synergistic interactions with AMB, FLU and itraconazole against $C$. albicans, but was only synergistic with $\mathrm{AMB}$, of the three drugs, against C. neoformans (Faria et al., 2011). A microarray analysis for detecting global gene expression of $S$. cerevisiae treated with thymol indicated increased expression of genes involved in drug efflux and iron uptake and repression of genes involved in ribosome biogenesis (Bi et al., 2010). The microarray results apparently did not present any significant indications that gene expression involving cell wall integrity was affected, unlike that found for filamentous fungi.

The papers cited above showed that essential oils from plants act as synergists of commercial antimycotics in vitro. The presumption might be that they are safe simply because of their historic use as spices, cosmetics or herbal medicines. One recent study, however, indicated that the essential oil of Ocimum sanctum (sacred basil), composed mainly of the monoterpene linalool, and the phenylpropene, methylchavicol, along with another 48 minor constituents, was non-toxic. This essential oil had a significant synergistic interaction $(\mathrm{FICI}<0.5)$ with both FLU and ketoconazole against experimental and clinical species and strains of Candida (Amber et al., 2010). This synergism resulted in overcoming resistance to FLU in some FLU-resistant strains. Moreover, a hemolysis bioassay of human red blood cells revealed that FLU and AMB had hemolytic activity far greater than that of the $O$. 
sanctum essential oil. It is possible that the mode of chemosensitizing activity of the essential oil of O. sanctum is due to its major constituent, methylchavicol. As cited above, the antifungal activity of another phenylpropene, anethole, was by inhibition of fungal chitin synthase (Yutani et al., 2011a). The combination of inhibitors of chitin and ergosterol biosynthesis by a phenylpropene (methylchavicol) and a triazole (FLU), respectively, may undermine fungal cell wall/membrane integrity.

Sesqui- and triterpenoids. The natural sesquiterpene alcohol, farnesol, has been shown to have synergistic interaction with FLU against C. albicans and C. dubliniensis. What makes farnesol even more intriguing is that it is actually a natural product of C. albicans involved in quorum-sensing for regulation of filamentation (Hornby et al., 2001; Oh et al., 2001). It was also determined that farnesol disrupts biofilm formation, a major infectivity component of these pathogens (Ramage et al., 2002). Sub-antifungal levels of azole antimycotic drugs cause an accumulation of farnesol, maintaining the pathogen in the yeast morph, and reducing biofilm formation and its infectivity (Hornby and Nickerson, 2004). In in vitro assays, addition of farnesol reversed resistance in FLU-resistant strains (Jabra-Rizk et al., 2006). In synergy tests, resistant strains ( $\geq 64 \mu \mathrm{g} \mathrm{mL}^{-1} \mathrm{FLU}$ ) were rendered susceptible $\left(<8 \mu \mathrm{g} \mathrm{mL}^{-1}\right)$ when both compounds were employed. Farnesol disrupted the plasma membrane integrity of these yeasts, rendering them more permeable to uptake of exogenous chemicals, such as antimycotic drugs. However, it was determined that farnesol triggers apoptosis (regulated cell-death) in C. albicans through a variety of mechanisms including production of reactive oxygen species (ROS), and hence oxidative stress, mitochondrial degradation and production of caspases, proteases associated with apoptosis (Shirtliff et al., 2009). A recent study, however, shows that genes within the ergosterol biosynthetic pathway are downregulated in farnesol treated $C$. albicans in association with increased sensitivity to FLU, suggesting an alternate or additional mode of action (Yu et al., 2012).

The pentacyclic triterpenoid, retigeric acid B, isolated from the lichen, Lobaria kurokawae, was recently found to be a potential antimycotic and/or chemosensitizing agent to azole antimycotics. L. kurokawae has been a component of Chinese folk medicine, but not directly in antifungal applications. Retigeric acid B showed a range in MICs of $8-16 \mu \mathrm{g} \mathrm{mL}^{-1}$ against clinical strains of C. albicans (Sun et al., 2009a). This level of antifungal activity is fairly high for a natural terpenoid/isoprene product in view that other such compounds discussed in this review require much higher anticandidal MICs of $100-300 \mu \mathrm{g} \mathrm{mL}^{-1}$. This same study also found that co-application of retigeric acid B with FLU, ketoconazole or itraconazole resulted in a significant synergistic antifungal interaction against azole-resistant strains of $C$. albicans. The antifungal and synergistic modes of action of retigeric acid $B$ include inhibition of efflux pump activity and ergosterol biosynthesis; which, in turn, undermines cell membrane integrity and cellular ion homeostasis (Sun et al., 2009b). The antifungal mode of action of retigeric acid B was investigated further and found to be associated with ROS related apoptosis (Chang et al., 2011). It was proposed that this apoptosis stemmed from inhibition of the sterol biosynthetic pathway with concomitant accumulation of farnesol leading to ROS production and apoptosis similar to that described by use of farnesol, alone (see above; Shirtliff et al., 2009).

There has been additional research on natural triterpenoids as chemosensitizing agents in antimycotic drug-resistant fungi. In all of these cases, the triterpenoid mode of action is disruption of efflux pump activity in strains of $S$. cerevisiae overexpressing C. albicans efflux pump genes such as MDR1 (belonging to the major facilitator superfamily) or CDR1 (belonging to the ATPbinding cassette superfamily). One of these triterpenoids was $9 \alpha$, $11 \alpha$-epoxycholest-7-ene-3 $\beta, 5,6,19$-tetrol 6-acetate (ECTA), isolated from the marine sponge, Dysidea arenaria (Jacob et al., 2003). In a strain of S. cerevisiae containing and overexpressing C. albicans MDR1, they found a 35 -fold decrease in FLU MICs (300-8.5 $\mu \mathrm{M})$ when ECTA was co-applied. Another group of triterpenoid inhibitors of efflux pump activity identified later by this group was the capisterones (Li et al., 2006). These compounds were isolated from the marine green alga, Penicillus capitatus. Like ECTA, they did not show innate antifungal activity, alone, but showed a synergistic interaction with FLU $($ FICI $<0.5)$ in both the CDR1- and MDR1-overexpressing strains of S. cerevisiae. A third group of sulfated triterpenoids from the marine sponge, Topsentia sp., was isolated by this group. Using the same screening tools plus additional clinical resistant strains of $C$. albicans overexpressing MDR1, they showed these sulfated sterols had similar synergistic characteristics as those triterpenoids previously tested (Digirolamo et al., 2009). Lastly, a triterpenoid, schinol, isolated from the plant, Schinus terebinthifolius, reacted synergistically with itraconazole, but not with AMB, against Paracoccidioides brasiliensis, the causative agent of systemic paracoccidioidomycosis (Johann et al., 2010).

Tea extracts, epigallocatechins, gallates, and polyphenols. One of earliest studies to detect synergistic interaction between natural products and antimycotic drugs involved alkylgallates and AMB. Of four natural antioxidants tested, at non-fungitoxic levels, propylgallate was found to enhance and prolong toxicity of $\mathrm{AMB}$ in vitro against a reference strain of $C$. albicans (ATCC 11651; Andrews et al., 1977). The mode of action of propylgallate, and the other less active antioxidants, was proposed as they stabilized the multiple double bonds of the polyene moiety of the drug. In testing propylgallate and AMB against more strains and species of Candida it was concluded that the antioxidant-based prolongation of AMB stability and the synergism by propylgallate were independent activities (Beggs et al., 1978a,b). Other phenolic derivatives that possess antioxidant activity, L-DOPA (L- $\beta$-3,4-dihydroxyphenylalanine) and dopamine (3,4-dihydroxyphenylethylamine) were soon identified to augment anticandidal efficacy of AMB, as well (Andrews et al., 1979). Because of the water solubility of these chemosensitizers, and their inherent safety as natural biochemical products, the authors felt they were natural candidates for in vivo or clinical testing. But, no results of such testing have been published.

Following Beggs' and Andrews' work, more natural compounds possessing intrinsic antioxidant activity were identified as stabilizers of AMB, but the work has largely gone unnoticed (Beggs, 1983). Propylgallate at non-fungicidal levels increased the 
antifungal activity in in vitro tests against clinical strains of $C$. albicans combined with imidazoles (Strippoli et al., 2000) and with triazoles (D'Auria et al., 2001). In these cases, it was speculated that propylgallate increased cell membrane porosity by interacting with membrane phospholipids and inhibited ABCtransporter drug efflux, allowing greater drug influx and retention. It was also proposed that propylgallate increased inhibition of P450-dependent lanosterol 14 $\alpha$-demethylase by azoles. Also, combinations of propylgallate and AMB, terbinafine, butenafine or ketoconazole were either synergistic or additive, and in one case antagonistic, depending on the drug and strain of filamentous fungus, chiefly species of Fusarium that are ocular pathogens (Xu et al., 2006).

Alkyl chain length of gallic acid esters can also affect antifungal activity and chemosensitization capacity. Of methyl, propyl, octyl, and decyl esters examined, in vitro, octyl was found to be the most potent against strains of A. flavus, A. fumigatus, and A. terreus when combined with AMB, FLU, or ketoconazole. This chemosensitizing capacity was determined to result from stressing the antioxidant system of the fungi (Kim et al., 2010a). This provides further evidence that such phenolic compounds augment antimycotic agents that cause oxidative stress in fungi. This would especially be the case in co-application with $\mathrm{AMB}$, which is now known to induce oxidative stress in fungi, in addition to causing plasma membrane leakage (Blum et al., 2008).

Extracts of tea, containing mainly polyphenolics, and especially epigallocatechin gallate (EGCG), possess significant antifungal activity against dermatophytic species of Trichophyton (Okubo et al., 1991), Trichophyton refractory to FLU or flucytosine (Park et al., 2011), and different infective species of Candida (Park et al., 2006). Activity of EGCG is highly pH dependent and under acidic conditions has significant synergistic activity with AMB or FLU, against both FLU- susceptible and resistant strains of C. albicans (Hirasawa and Takada, 2004). Murine model assays (BALB/c) showed that mice with disseminated candidiasis given EGCG (at $2 \mathrm{mg} \mathrm{kg}^{-1} \mathrm{bw}$ ) intraperitoneally and AMB (at $0.5 \mathrm{mg} \mathrm{kg}^{-1}$ bw) survived 4 weeks longer than those given AMB therapy, alone (Han, 2007a). Almost identical results occurred when extracts of grape seed, also rich in polyphenols such as EGCG and proanthocyanidins, were administered with $\mathrm{AMB}$ in a parallel murine assay (Han, 2007b). The probable mode of action of synergism of EGCG to both AMB and FLU is that EGCG is an inhibitor of dihydrofolate reductase in $C$. albicans and is thus an antifolate (Navarro-Martinez et al., 2006). This disruption of the folic acid cycle, in turn, inhibits the ergosterol biosynthetic pathway resulting in an additional stress to cell membrane/wall integrity after exposure to either AMB or triazole antimycotics.

Curcumin, a symmetrical diphenolic compound rendering the yellow pigment to turmeric, was noted to have greater antifungal activity against $P$. brasiliensis than FLU, with nominal activity against clinical strains of Candida, Aspergillus, and C. neoformans (Martins et al., 2009). It was determined that curcumin induced oxidative stress, leading to apoptosis. Curcumin treatment of $C$. albicans resulted in elevated levels of ROS and concomitant upregulation in expression of several genes associated with fungal oxidative stress, including superoxide dismutase, catalase, and oxidoreductase (Sharma et al., 2010b). It was recently reported that when curcumin was co-applied at non-fungicidal levels with any of five azole drugs (FLU, miconazole, ketoconazole, itraconazole, or voriconazole) or two polyenes (nystatin and AMB) against 21 strains of $C$. albicans having some resistance to these drugs, all interactions were synergistic (FICIs 0.09-0.5) with MIC dosages of the antimycotics being reduced by 10 - to 35 -fold (Sharma et al., 2010a).

Non-phenolic plant natural product chemosensitizers. There has been a great deal of interest over the potential use of natural products from garlic (Allium sativum) as antimycotics, either directly or as chemosensitizers (Davis, 2005). Extracts of garlic, and the compounds within, were successfully used to treat cases of cerebrospinal cryptococcosis via intravenous administration to patients in the People's Republic of China (Davis et al., 1990). The raw extracts of garlic were also found to have antifungal activity against Scedosporium prolificans, an invasive fungal pathogen that is resistant to all available antimycotic drugs (Davis et al., 2003). Synergistic interaction between diallyl trisulfide, from garlic, combined with AMB, was found against C. neoformans (Shen et al., 1996), another early example, in addition to propylgallate mentioned above, of a natural product as an antimycotic chemosensitizer. A later study of the essential oil from A. sativum combined with ketoconazole showed synergistic antifungal activity against three dermatophytic species of Trichophyton (Pyun and Shin, 2006).

The mode of antifungal and chemosensitizing action of allicin, an allyl-sulfur compound from garlic, has been determined. Combinations of allicin and AMB result in a highly synergistic antifungal interaction against S. cerevisiae (Ogita et al., 2006) and C. albicans (Borjihan et al., 2009). Allicin specifically enhances $\mathrm{AMB}$ vacuolar disruption in fungi when ergosterol is present in the membrane to which $\mathrm{AMB}$ can bind. If ergosterol is not present, as in erg6 $\Delta$ mutants of $S$. cerevisiae, the fungus is resistant to both AMB, with or without allicin present (Ogita et al., 2010). In vitro assays of combinations of FLU and allicin of 24 FLUresistant strains of $C$. albicans showed 23 synergistic interactions. In in vivo assays, using a $\mathrm{BALB} / \mathrm{c}$ murine model of candidiasis, cohorts receiving FLU and FLU + allicin survived equivalently, however, the infection load in kidney biopsies was significantly lower in the FLU + allicin cohort (Guo et al., 2010). Examination of global expression of genes of S. cerevisiae treated with allicin revealed a multifaceted effect on genes involved in sulfur amino acid metabolism, gene repair and the oxidative stress response pathway (Yu et al., 2010).

Berberine is a benzodioxoloquinolizine alkaloid mainly found in various plants in the families Berberidaceae, such as shrubs native to southern Europe, or Ranunculaceae, such as goldthread, Coptis chinensis, native to China. Berberine, extracted from roots of goldthread, has a long history as an antifungal agent in Chinese folk medicine (Creasy, 1979). However, berberine was specifically reported to have anticandidal activity and its combination with AMB is synergistic (Han and Lee, 2005). In one of the rare studies of a natural chemosensitizer with a commercial antimycotic drug in mouse bioassays, it was found that cohorts having disseminated C. albicans candidiasis that received berberine $+\mathrm{AMB}$ survived more than twice as long as those receiving AMB, alone. Moreover, 
to achieve the same duration of survival as the $\mathrm{AMB}+$ berberine cohort four-times the AMB dose, alone, was required. Combination of berberine and FLU resulted in a synergistic interaction against FLU-resistant strains of $C$. albicans, with MICs $>64 \mu \mathrm{g} \mathrm{mL}^{-1}$ of FLU reduced to $<2 \mu \mathrm{g} \mathrm{mL}^{-1}$ and FICIs $<0.13$ in combination with berberine (Quan et al., 2006).

The mode of action of berberine appears to be induction of oxidative stress, as demonstrated with two commercial agricultural fungicides, strobilurin and fludioxonil. Strobilurin targets complex III of the mitochondrial respiratory pathway, while fludioxonil targets the MAPK system associated with osmoregulation, in filamentous fungi. Activity of strobilurin was elevated by co-application with berberine in A. fumigatus wild-type and resistant MAPK mutants. The study showed that berberine disrupted Mn-SOD (mitochondrial superoxide dismutase) required for detoxification of ROS produced from the inhibition of mitochondrial respiration by strobilurin. Furthermore, this additional oxidative stress induced by berberine also resulted in overcoming resistance to fludioxonil (Kim et al., 2007a).

These findings were supported by a later study involving proteomic analyses of C. albicans strains, resistant to FLU. When these strains were treated with a combination of FLU and berberine, proteomic profiles revealed they affected mitochondrial respiration, resulting in a significant production of ROS (Xu et al., 2009). This activity was reversed by addition of either ascorbic acid or reduced glutathione. An additional study also showed synergism between berberine and FLU, in vitro, against clinical isolates of C. albicans (Iwasaki et al., 2010). However, it was most recently shown that a combination of berberine and itraconazole was antagonistic against clinical strains of A. fumigatus (Lei et al., 2011). This antagonism was suggested to result from competition between berberine and itraconazole in disrupting ergosterol biosynthesis.

\section{Synthetic antifungal chemosensitizers}

Amiodarone, a complex benzofuran, was originally identified for clinical use to treat heart arrhythmia (Singh and Vaughan Williams, 1970). However, it was later found to have some nominal antifungal activity against Aspergillus, Candida, and Cryptococcus (Courchesne, 2002). In an in vitro study against itraconazole- susceptible and resistant strains of A. fumigatus, amiodarone and itraconazole were highly synergistic, mainly in itraconazole-resistant strains, achieving an FICI as low as 0.02 with one strain (Afeltra et al., 2004). It was believed that this synergism resulted from disruption of sodium ion transport. Amiodarone was next found to be highly synergistic to FLU, itraconazole and voriconazole against azole-resistant strains of C. albicans, with FICIs from 0.001 to 0.018 (Guo et al., 2008). However, in combination with azoles against susceptible strains, interactions were mainly neutral or, in a few cases, antagonistic. The basis of synergism between amiodarone and FLU based on gene expression profiling revealed that amiodarone toxicity, alone, to C. albicans was disruption of $\mathrm{Ca}^{2+}$ homeostasis (Gamarra et al., 2010). However, when amiodarone and FLU were combined, expression of genes normally upregulated to respond to the stresses introduced by either compound, alone, were attenuated. This suggested that there was some type of compensatory inhibition of response pathways to counteract the stresses of either compound. Overall, the outcome of this interaction was loss of membrane integrity resulting from diminished ergosterol availability and cellular ion imbalance. The synergism of amiodarone and FLU was also reflected in murine model assays, where cohorts receiving both drugs showed a $>4$-log reduction of CFU in kidney biopsies when infected with FLU-resistant C. albicans.

Another synthetic compound being tested as a potential chemosensitizing agent to antimycotic drugs is 7chlorotetrazolo[5,1-c]benzo[1,2,4] triazine (CTBT). CTBT was first identified as a potential chemosensitizer during screening of synthetic compounds using the multidrug resistant mutant $S$. cerevisiae pdr 3-9 (Cernicka et al., 2007). CTBT itself possesses nominal fungicidal activity and its fungitoxicity does not target the pleiotropic drug regulator genes, PDR1 and PDR3. However, in combination with FLU, the MIC of FLU was reduced by twofold in drug sensitive and resistant $C$. albicans. The chemosensitizing effect was also independent of genes associated with multidrug resistance, including efflux pumps, in yeasts; which a number of other synthetic potential chemosensitizing agents do disrupt (Cernicka et al., 2007; references therein). The chemosensitizing effect of CTBT was later identified, based on gene mutant hypersensitivity assays, to result from induction of oxidative stress. Similar to natural benzaldehyde analogs discussed above, CTBT appears to specifically target mitochondria, as represented by hypersensitivity of $\operatorname{sod} 2 \Delta$ mutants and production of ROS (Batova et al., 2010). CTBT was also identified to be a potent chemosensitizing agent in combination with itraconazole against $A$. niger, again resulting from inducing oxidative stress (Culakova et al., 2012).

The synthetic compounds gemfibrozil, quinine, and chlorpromazine, defined as "chemosensitizers," were found to reduce the MICs of FLU by sevenfold against reference and clinical strains of C. albicans (Bulatova and Darwish, 2008). A number of iron-chelating compounds were found to enhance activity of antimycotics against $A$. fumigatus. These included ciclopirox and deferiprone in combination with ketoconazole, lactoferrin with AMB, and deferiprone with FLU (Zarember et al., 2009). Triclosan, a synthetic chlorinated aromatic compound known to have antimicrobial activity, was found to synergistically enhance the activity of FLU against all 24 azole-resistant strains of C. albicans examined (Yu et al., 2011).

Another tactic for overcoming antifungal drug resistance, or enhancing efficacy, has involved targeting Hsp90, a molecular chaperone linked to fungal resistance to both azoles and echinocandins. Hsp90 is an intermediate in the PKC pathway governing the stress response to cell wall integrity (LaFayette et al., 2010). A number of Hsp90 inhibitors related to geldanamycin, a benzoquinone showing antitumor activity, were tested as antifungal and "chemosensitizing" agents. Both in vitro and in vivo assays showed that Hsp90 inhibitors have the potential to enhance the activity of azoles and echinocandins, and overcome any resistance, to either. In vitro assays using a FLU-resistant strain of C. albicans showed that addition of geldanamycin, or synthetic structural analogs 17-(allylamino)- or 17-(dimethylaminoethylamino)- 17demethoxygeldanamycin with FLU overcame resistance and also enhanced activity of caspofungin against $A$. fumigatus and $A$. terreus. These same Hsp90 inhibitors also showed synergistic interaction with caspofungin or FLU against A. fumigatus or C. albicans, 
respectively, in in vivo insect model assays, at levels where neither of the compounds, alone, had antifungal activity (Cowen, 2009; Cowen et al., 2009; Singh et al., 2009).

A number of alkyl guanidine analogs, substructures of polyol antibiotics, were examined for direct fungitoxicity and synergism with AMB. One analog, $N$-methyl- $N^{\prime}$-dodecylguanidine was found to be a potent synergist of $\mathrm{AMB}$ against $S$. cerevisiae (Ogita et al., 2007). The synergism was initially identified to be associated with disruption of the plasma membrane and generation of ROS. In a recent examination of this compound in combination with AMB against $C$. albicans, it was determined that $N$-methyl$N^{\prime}$-dodecylguanidine disrupted ergosterol related activities with regard to the vacuolar membrane, thus enhancing the fungicidal effect of AMB (Yutani et al., 2011b).

Certain peptides examined recently may provide a synergistic elevation of antimycotic activity of selected drugs. Five cationic antimicrobial peptides were tested in combination with the echinocandins, caspofungin and anidulafungin, against reference and clinical strains of C. albicans and C. glabrata (Harris and Coote, 2010). Of these peptides, dermaseptin S3(1-16) and ranalexin were found to have the broadest degree of synergistic interactions with the echinocandins in all strains tested. However, in murine bioassays of systemic candidiasis using ranalexin and caspofungin, no synergism was detected.

One of the more novel approaches in the use of synthetic compounds to augment antimycotic activity of drugs involves compounds for use in so-called photodynamic therapy (PDT). PDT agents are compounds that are reactive with visible light and result in the production of ROS (Mizuno et al., 2011). They have been proposed as potential antimicrobial agents for treatment of cutaneous or mucocutaneous mycoses, infections in tissue in which light can penetrate to some degree. It had been previously shown that elevation of ROS enhances anticandidal activity of PDTs (Chabrier-Rosello et al., 2008). In a test of several PDT agents and azole drugs, used to enhance ROS production, the combination of miconazole and a PDT agent, the porphyrin TMP-1363, resulted in prolonging fungistasis against C. albicans, in vitro (Snell et al., 2011). However, this synergism and its association to elevated ROS production were not clearly determined.

Lastly, a new class of synthetic bromine-containing compounds has been shown to have specific, potent antifungal activity by targeting the fungal sphingolipid pathway. These are currently undergoing clinical evaluation. One of these compounds, $N^{\prime}$-(3-bromo4-hydroxybenzylidene)-2-methylbenzohydrazide (BHBM), has been found to have a synergistic interaction with FLU $($ FICI $=0.5)$ against C. neoformans (Dr. Maurizio Del Poeta, personal communication).

\section{CONCLUSION AND PERSPECTIVES}

In the course of reviewing the literature for this chapter it was striking how often one found almost "boiler plate" type of statements. Frequently the first paragraph of most papers cited the emerging crisis of resistance to antifungal agents and the slow progress in developing new ones. And, in an almost universal "chorus," the paper would state how important is to perform studies on chemosensitization to develop new antifungal modes of action, or new fungal control strategies. Then, almost universally, the theme of the final paragraph would end with a statement to the effect of, "the results of this study show a promising new strategy for control of fungal diseases. Further field/clinical studies are warranted. .."

The term "chemosensitization" has a number of synonyms in the literature, including: "synergizers, enhancers, augmenting agents, sensitizers, potentiators" and others. There are inherent difficulties in developing antifungal agents that are also not toxic to the patient. Additional problems in the clinical treatment of mycoses are the frustrating frequency with which target cells develop resistance and, in some cases, there is deep-seated and widespread invasiveness of the infections within the patient. These factors result in the need for high doses of drugs to achieve effectiveness at the fungal infection site, which should strongly support research efforts on chemosensitizing agents.

However, there are a number of perplexing attributes concerning the literature on chemosensitization research on antifungal agents. One of the first to be noted was the fair amount of research in this area being pursued in "pockets," throughout the globe. However, by virtue of the fact that many researchers were not citing each other's work it seemed that many researchers were simply unaware of each other. This oversight, however, within the past year has begun to be remedied. But, to date, no conferences, workshops or books have specifically focused on antifungal chemosensitization.

With regard to what appears in most chemosensitization research papers in their final paragraph, all of the papers cited, here, emphasized the prospects for continuation of the research with field or clinical trials (depending upon agriculture or medicine). Despite the fact that the first papers on antifungal chemosensitization appeared over three decades ago, to date only a handful of papers have presented results beyond in vitro Petri dish or microtiter plate assays. A scant few have presented any in vivo results, all of which were murine or insect model assays, three showing successful enhancement, allicin + FLU, berberine $+\mathrm{AMB}$, amiodarone $+\mathrm{FLU}$, and one showing neutrality, caspofungin + ranalexin and Hsp90 inhibitors + AMB. To date, no clinical trials on antifungal chemosensitization have been reported in the literature; though there are two where chemosensitizers have gone through clinical tests as antifungal agents, alone, EGCG and garlic extracts.

It is perplexing as to why, after three decades of promising results on chemosensitization of antifungal agents, nothing has reached the field or clinical stage of trial. One possibility is that many of the chemosensitizing agents lack specificity to fungi. Many of them are generally mildly antimicrobial, or have broader biocidal activity, being antihelminthic or even insecticidal, but only at rates that far exceed those of their commercial counterparts. This absence of specificity may be a harbinger of potential toxicity to the host (crop/human patient). However, many of the chemosensitizing agents discussed are natural compounds found in spices used in human cuisine, or have been used in folk medicine for centuries. But, many of these "natural" chemosensitizers have never undergone mammalian toxicity testing beyond the oral level; which would include intravenous or intraperitoneal tests.

We are now beginning to see a new group of antifungal chemosensitizers. These are the synthetic compounds. Perhaps, 
as these show more promise and greater specificity toward fungi, there will be a greater commercial and/or clinical interest in developing them for use in concert with appropriate commercial antifungal agents. It is with this in mind that some encouragement

\section{REFERENCES}

Afeltra, J., Vitale, R. G., Mouton, J. W., and Verweij, P. E. (2004). Potent synergistic in vitro interaction between nonantimicrobial membrane-active compounds and itraconazole against clinical isolates of Aspergillus fumigatus resistant to itraconazole. Antimicrob. Agents Chemother. 48, 1335-1343.

Ahmad, A., Khan, A., Khan, L. A., and Manzoor, N. (2010a). In vitro synergy of eugenol and methyleugenol with fluconazole against clinical Candida isolates. J. Med. Microbiol. 59, 1178-1184.

Ahmad, A., Khan, A., Yousuf, S., Khan, L. A., and Manzoor, N. (2010b). Proton translocating ATPase mediated fungicidal activity of eugenol and thymol. Fitoterapia 81, 1157-1162.

Amber, K., Aijaz, A., Immaculata, X., Luqman, K. A., and Nikhat, M. (2010). Anticandidal effect of Ocimum sanctum essential oil and its synergy with fluconazole and ketoconazole. Phytomedicine 17, 921-925.

Anderson, J. B. (2005). Evolution of antifungal-drug resistance: mechanisms and pathogen fitness. Nat. Rev. Microbiol. 3, 547-556.

Andrews, F. A., Beggs, W. H., and Sarosi, G. A. (1977). Influence of antioxidants on the bioactivity of amphotericin B. Antimicrob. Agents Chemother. 11, 615-618.

Andrews, F. A., Sarosi, G. A., and Beggs, W. H. (1979). Enhancement of amphotericin B activity by a series of compounds related to phenolic antioxidants. J. Antimicrob. Chemother. 5, 173-177.

Arora, D. S., and Kaur, J. (1999). Antimicrobial activity of spices. Int. J. Antimicrob. Agents 12, 257-262.

Baddley, J. W., and Pappas, P. G. (2005). Antifungal combination therapy: clinical potential. Drugs 65, 1461-1480.

Bang, K. H., Lee, D. W., Park, H. M., and Rhee, Y. H. (2000). Inhibition of fungal cell wall synthesizing enzymes by trans-cinnamaldehyde. Biosci. Biotechnol. Biochem. 64, 1061-1063.

Batova, M., Klobucnikova, V., Oblasova, Z., Gregan, J., Zahradnik, P., Hapala, I., Subik, J., and Schuller, C. (2010). Chemogenomic and transcriptome analysis identifies mode of action of the chemosensitizing agent CTBT (7-chlorotetrazolo [5,1-c]benzo[ $[1,2,4]$ triazine $). \quad B M C$ Genomics 11, 153. doi:10.1186/14712164-11-153

Beggs, W. H. (1983). Antioxidantstabilized amphotericin B. Diagn. Microbiol. Infect. Dis. 1, 339-341.

Beggs, W. H., Andrews, F. A., and Sarosi, G. A. (1978a). Antioxidant enhancement of amphotericin B activity against Candida albicans. Res. Commun. Chem. Pathol. Pharmacol. 20, 409-412.

Beggs, W. H., Andrews, F. A., and Sarosi, G. A. (1978b). Synergistic action of amphotericin B and antioxidants against certain opportunistic yeast pathogens. Antimicrob. Agents Chemother. 13, 266-270.

Ben-Ami, R., Garcia-Effron, G., Lewis, R. E., Gamarra, S., Leventakos, K., Perlin, D. S., and Kontoyiannis, D. P. (2011). Fitness and virulence costs of Candida albicans FKS1 hot spot mutations associated with echinocandin resistance. J. Infect. Dis. 204, 626-635.

Benet, T., Nicolle, M. C., Thiebaut, A., Piens, M. A., Nicolini, F. E., Thomas, hems, P. (2007). Reduction of invasive aspergillosis incidence among immunocompromised patients after control of environmental exposure. Clin. Infect. Dis. 45, 682-686.

Beuchat, L. R. (1994). "Antimicrobial properties of spices and their essential oils," in Natural Antimicrobial Systems and Food Preservation, eds V. M. Dillon and R. G. Board (Oxon: CAB International), 99-131.

Bi, X., Guo, N., Jin, J., Liu, J., Feng, H., Shi, J., Xiang, H., Wu, X., Dong, J., $\mathrm{Hu}, \mathrm{H}$., Yan, S., Yu, C., Wang, X., Deng, X., and Yu, L. (2010). The global gene expression profile of the model fungus Saccharomyces cerevisiae induced by thymol. J. Appl. Microbiol. 108, 712-722.

Bicanic, T., Meintjes, G., Wood, R., Hayes, M., Rebe, K., Bekker, L. G., and Harrison, T. (2007). Fungal burden, early fungicidal activity, and outcome in cryptococcal meningitis in antiretroviral-naive or antiretroviral-experienced patients treated with amphotericin B or fluconazole. Clin. Infect. Dis. 45, 76-80.

Blum, G., Perkhofer, S., Haas, H., Schrettl, M., Wurzner, R., Dierich, M. P., and Lass-Florl, C. (2008). Potential basis for amphotericin B resistance in Aspergillus terreus. X., Picot, S., Michallet, M., and Van-

should be placed upon a closer relationship between industry, academia and government labs to look further into the promising attributes of chemosensitizing agents to improve efficacy of available antifungal agents.

Antimicrob. Agents Chemother. 52, 1553-1555.

Borjihan, H., Ogita, A., Fujita, K., Hirasawa, E., and Tanaka, T. (2009). The vacuole-targeting fungicidal activity of amphotericin B against the pathogenic fungus Candida albicans and its enhancement by allicin. J. Antibiot. 62, 691-697.

Braga, P. C., Sasso, M. D., Culici, M. and Alfieri, M. (2007). Eugenol and thymol, alone or in combination, induce morphological alterations in the envelope of Candida albicans. Fitoterapia 78, 396-400.

Brent, K. J. (1995). Fungicide Resistance in Crop Pathogens: How can it be Managed. FRAC Monograph No. 1. Brussels: GIFAP.

Brent, K. J., and Hollomon, D. W. (2007). Fungicide Resistance in Crop Pathogens: How can it be Managed? FRAC Monograph No. 1, 2nd Edn. Brussels: CropLife International.

Bulatova, N. R., and Darwish, R. M. (2008). Effect of chemosensitizers on minimum inhibitory concentrations of fluconazole in Candida albicans. Med. Princ. Pract. 17, 117-121.

Camps, S. M. T., van der Linden, J. W. M., Li, Y., Kuijper, E. J., van Dissel, J. T., Verweij, P. E., and Melchers, W. J. G. (2012). Rapid induction of multiple resistance mechanisms in Aspergillus fumigatus during azole therapy: a case study and review of the literature. Antimicrob. Agents Chemother. 56, 10-16.

Cannon, R. D., Lamping, E., Holmes, A. R., Niimi, K., Baret, P. V., Keniya, M. V., Tanabe, K., Niimi, M., Goffeau, A., and Monk, B. C. (2009). Effluxmediated antifungal drug resistance. Clin. Microbiol. Rev. 22, 291-321.

Cass, A., Finkelstein, A., and Krespi, V. (1970). The ion permeability induced in thin lipid membranes by the polyene antibiotics nystatin and amphotericin B. J. Gen. Physiol. 56, 100-124.

Cernicka, J., Kozovska, Z., Hnatova, M., Valachovic, M., Hapala, I., Riedl, Z., Hajos, G., and Subik, J. (2007). Chemosensitisation of drugresistant and drug-sensitive yeast cells to antifungals. Int. J. Antimicrob. Agents 29, 170-178.

Chabrier-Rosello, Y., Foster, T. H., Mitra, S., and Haidaris, C. G. (2008). Respiratory deficiency enhances the sensitivity of the pathogenic fungus Candida to photodynamic treatment. Photochem. Photobiol. 84, 1141-1148.

Chandenier, J., Adou-Bryn, K. D., Douchet, C., Sar, B., Kombila, M., Swinne, D., Therizol-Ferly, M., Buisson, Y., and Richard-Lenoble, D. (2004). In vitro activity of amphotericin B, fluconazole and voriconazole against 162 Cryptococcus neoformans isolates from Africa and Cambodia. Eur. J. Clin. Microbiol. Infect. Dis. 23, 506-508.

Chang, W. Q., Wu, X. Z., Cheng, A. X., Zhang, L., Ji, M., and Lou, H. X. (2011). Retigeric acid B exerts antifungal effect through enhanced reactive oxygen species and decreased cAMP. Biochim. Biophys. Acta 1810, 569-576.

Chaturvedi, V., Ramani, R., Andes, D., Diekema, D. J., Pfaller, M. A., Ghannoum, M. A., Knapp, C., Lockhart, S. R., Ostrosky-Zeichner, L., Walsh, T. J., Marchillo, K., Messer, S., Welshenbaugh, A. R., Bastulli, C., Iqbal, N., Paetznick, V. L., Rodriguez, J., and Sein, T. (2011). Multilaboratory testing of two-drug combinations of antifungals against Candida albicans, Candida glabrata, and Candida parapsilosis. Antimicrob. Agents Chemother. 55, 1543-1548.

Clinical and Laboratory Standards Institute (CLSI). (2008a). Reference Method for Broth Dilution Antifungal Susceptibility Testing of Filamentous Fungi: Approved Standard-Second Edition. CLSI Document M38-A2. Wayne, PA: Clinical and Laboratory Standards Institute.

Clinical and Laboratory Standards Institute (CLSI). (2008b). Reference Method for Broth Dilution Antifungal Susceptibility Testing of Yeasts; Approved Standard- Third Edition. CLSI Document M27-A3. Wayne, PA: Clinical Laboratory Standards Institute.

Copping, L. G., and Duke, S. O. (2007). Natural products that have been used commercially as crop protection agents. Pest Manag. Sci. 63, 524-554.

Cornelissen, B., and Melchers, L. S. (1993). Strategies for control of fungal diseases with transgenic plants. Plant Physiol. 101, 709-712.

Courchesne, W. E. (2002). Characterization of a novel, broad-based fungicidal activity for the antiarrhythmic drug amiodarone. J. Pharmacol. Exp. Ther. 300, 195-199. 
Cowen, L. E. (2009). Hsp90 orchestrates stress response signaling governing fungal drug resistance. PLoS Pathog. 5, el000471. doi:1000410.1001371/journal.ppat.1000471

Cowen, L. E., Singh, S. D., Kohler, J. R., Collins, C., Zaas, A. K., Schell, W. A., Aziz, H., Mylonakis, E., Perfect, J. R., Whitesell, L., and Lindquist, S. (2009). Harnessing Hsp90 function as a powerful, broadly effective therapeutic strategy for fungal infectious disease. Proc. Natl. Acad. Sci. U.S.A. 106, 2818-2823.

Creasy, W. A. (1979). Biochemical effects of berberine. Biochem. Pharmacol. 28, 1081-1084.

Cuenca-Estrella, M. (2004). Combinations of antifungal agents in therapy - what value are they? J. Antimicrob. Chemother. 54, 854-869.

Culakova, H., Dzugasova, V., Gbelska, Y., and Subik, J. (2012). CTBT (7-chlorotetrazole[5,1c]benzo[1,2,4]triazine) producing ROS affects growth and viability of filamentous fungi. FEMS Microbiol. Lett. 328, 138-143.

D'Auria, F. D., Tecca, M., Strippoli, R., and Simonetti, N. (2001). In vitro activity of propyl gallate-azole drug combination against fluconazoleand itraconazole-resistant Candida albicans strains. Lett. Appl. Microbiol. 32, 220-223.

Davis, L. E., Shen, J. K., and Cai, Y. (1990). Antifungal activity in human cerebrospinal fluid and plasma after intravenous administration of Allium sativum. Antimicrob. Agents Chemother. 34, 651-653.

Davis, S. R. (2005). An overview of the antifungal properties of allicin and its breakdown products - the possibility of a safe and effective antifungal prophylactic. Mycoses 48, 95-100.

Davis, S. R., Perrie, R., and Apitz-Castro, R. (2003). The in vitro susceptibility of Scedosporium prolificans to ajoene, allitridium and a raw extract of garlic (Allium sativum). J. Antimicrob. Chemother. 51, 593-597.

Deising, H. B., Reimann, S., and Pascholati, S. F. (2008). Mechanisms and significance of fungicide resistance. Braz. J. Microbiol. 39, 286-295.

Del Sorbo, G., Schoonbeek, H., and De Waard, M. A. (2000). Fungal transporters involved in efflux of natural toxic compounds and fungicides. Fungal Genet. Biol. 30, $1-15$.

Digirolamo, J. A., Li, X. C., Jacob, M. R., Clark, A. M., and Ferreira, D.
(2009). Reversal of fluconazole resistance by sulfated sterols from the marine sponge Topsentia sp. J. Nat. Prod. 72, 1524-1528.

Dutcher, J. D. (1968). The discovery and development of amphotericin B. Dis. Chest 54(Suppl. 1), 296-298.

Eschenauer, G., Depestel, D. D., and Carver, P. L. (2007). Comparison of echinocandin antifungals. Ther. Clin. Risk Manag. 3, 71-97.

Espinel-Ingroff, A. (2009). Novel antifungal agents, targets or therapeutic strategies for the treatment of invasive fungal diseases: a review of the literature (2005-2009). Rev. Iberoam. Micol. 26, 15-22.

European Committee on Antimicrobial Susceptibility Testing (EUCAST). (2008a). EUCAST definitive document E.DEF 9.1: method for the determination of broth dilution minimum inhibitory concentrations of antifungal agents for conidia forming moulds. Eur. J. Clin. Microbiol. Infect. Dis. 9.1, 1-13.

European Committee on Antimicrobial Susceptibility Testing (EUCAST). (2008b). EUCAST definitive document EDef 7.1: method for the determination of broth dilution MICs of antifungal agents for fermentative yeasts. Eur. J. Clin. Microbiol. Infect. Dis. 14, 398-405.

Faria, N. C., Kim, J. H., Goncalves, L. A., Martins Mde, L., Chan, K. L., and Campbell, B. C. (2011). Enhanced activity of antifungal drugs using natural phenolics against yeast strains of Candida and Cryptococcus. Lett. Appl. Microbiol. 52, 506-513.

Fontenelle, R. O. S., Morais, S. M., Brito, E. H. S., Brilhante, R. S. N., Cordeiro, R. A., Lima, Y. C., Brasil, N. V. G. P. S., Monteiro, A. J., Sidrim, J. J. C., and Rocha, M. F. G. (2011). Alkylphenol activity against Candida spp. and Microsporum canis: a focus on the antifungal activity of thymol, eugenol and O-methyl derivatives. Molecules 16, 6422-6431.

Ford, J. M., and Hait, W. N. (1993). Pharmacologic circumvention of multidrug resistance. Cytotechnology 12, 171-212.

Förster, H., Driever, G. F., Thompson, D. C., and Adaskaveg, J. E. (2007). Postharvest decay management for stone fruit crops in California using the "reduced-risk" fungicides fludioxonil and fenhexamid. Plant Dis. 91, 209-215.

Gamarra, S., Rocha, E. M., Zhang, Y. Q., Park, S., Rao, R., and Perlin, D. S. (2010). Mechanism of the synergistic effect of amiodarone and fluconazole in Candida albicans.
Antimicrob. Agents Chemother. 54, 1753-1761.

Giordani, R., Regli, P., Kaloustian, J., Mikail, C., Abou, L., and Portugal, H. (2004). Antifungal effect of various essential oils against Candida albicans. Potentiation of antifungal action of amphotericin B by essential oil from Thymus vulgaris. Phytother. Res. 18, 990-995.

Giordani, R., Regli, P., Kaloustian, J., and Portugal, H. (2006). Potentiation of antifungal activity of amphotericin B by essential oil from Cinnamomum cassia. Phytother. Res. 20, 58-61.

Giordani, R., Trebaux, J., Masi, M., and Regli, P. (2001). Enhanced antifungal activity of ketoconazole by Euphorbia characias latex against Candida albicans. J. Ethnopharmacol. 78, 1-5.

Gisi, U., Sierotzki, H., Cook, A., and McCaffery, A. (2002). Mechanisms influencing the evolution of resistance to Qo inhibitor fungicides. Pest Manag. Sci. 58, 859-867.

Grosso, C., Figueiredo, A. C., Burillo, J., Mainar, A. M., Urieta, J. S., Barroso, J. G., Coelho, J. A., and Palavra, A. M. (2009). Supercritical fluid extraction of the volatile oil from Santolina chamaecyparissus. J. Sep. Sci. 32, 3215-3222.

Guo, N., Liu, J., Wu, X., Bi, X., Meng, R., Wang, X., Xiang, H., Deng, X., and Yu, L. (2009). Antifungal activity of thymol against clinical isolates of fluconazole-sensitive and -resistant Candida albicans. J. Med. Microbiol. 58, 1074-1079.

Guo, N., Wu, X., Yu, L., Liu, J., Meng, R. Jin, J., Lu, H., Wang, X., Yan, S., and Deng, X. (2010). In vitro and in vivo interactions between fluconazole and allicin against clinical isolates of fluconazole-resistant Candida albicans determined by alternative methods. FEMS Immunol. Med. Microbiol. 58, 193-201.

Guo, Q., Sun, S., Yu, J., Li, Y., and Cao, L. (2008). Synergistic activity of azoles with amiodarone against clinically resistant Candida albicans tested by chequerboard and timekill methods. J. Med. Microbiol. 57, 457-462.

Han, L., Zheng, D., Huang, X. S., Yu, S. S., and Liang, X. T. (2007). Natural products in clinical trials: antibacterial and antifungal agents. Yao Xue Xue Bao 42, 236-244.

Han, Y. (2007a). Synergic anticandidal effect of epigallocatechin-Ogallate combined with amphotericin $\mathrm{B}$ in a murine model of disseminated candidiasis and its anticandidal mechanism. Biol. Pharm. Bull. 30, 1693-1696.
Han, Y. (2007b). Synergic effect of grape seed extract with amphotericin B against disseminated candidiasis due to Candida albicans. Phytomedicine 14, 733-738.

Han, Y., and Lee, J. H. (2005). Berberine synergy with amphotericin B against disseminated candidiasis in mice. Biol. Pharm. Bull. 28, 541-544.

Harris, M. R., and Coote, P. J. (2010). Combination of caspofungin or anidulafungin with antimicrobial peptides results in potent synergistic killing of Candida albicans and Candida glabrata in vitro. Int. J. Antimicrob. Agents 35, 347-356.

Hemaiswarya, S., Kruthiventi, A. K., and Doble, M. (2008). Synergism between natural products and antibiotics against infectious diseases. Phytomedicine 15, 639-652.

Hirasawa, M., and Takada, K. (2004). Multiple effects of green tea catechin on the antifungal activity of antimycotics against Candida albicans. J. Antimicrob. Chemother. 53, 225-229.

Hope, W. W., Tabernero, L., Denning, D. W., and Anderson, M. J. (2004). Molecular mechanisms of primary resistance to flucytosine in Candida albicans. Antimicrob. Agents Chemother. 48, 4377-4386.

Hornby, J. M., Jensen, E. C., Lisec, A. D., Tasto, J. J., Jahnke, B., Shoemaker, R., Dussault, P., and Nickerson, K. W. (2001). Quorum sensing in the dimorphic fungus Candida albicans is mediated by farnesol. Appl. Environ. Microbiol. 67, 2982-2992.

Hornby, J. M., and Nickerson, K. W. (2004). Enhanced production of farnesol by Candida albicans treated with four azoles. Antimicrob. Agents Chemother. 48, 2305-2307.

Horsfall, J. G. (1975). Fungi and fungicides: the story of a nonconformist. Annu. Rev. Phytopathol. 13, 1-14.

Hsu, F. L., Chang, H. T., and Chang, S. T. (2007). Evaluation of antifungal properties of octyl gallate and its synergy with cinnamaldehyde. Bioresour. Technol. 98, 734-738.

Isenberg, H. D. (1992). Clinical Microbiology Procedures Handbook. Washington, DC: American Society of Microbiology.

Iwasaki, R. S., Endo, E. H., UedaNakamura, T., Nakamura, C. V., Garcia, L. B., and Filho, B. P. D. (2010). In vitro antifungal activity of the berberine and its synergism with fluconazole. J. Microbiol. 97, 201-205.

Jabra-Rizk, M. A., Shirtliff, M., James, C., and Meiller, T. (2006). Effect of farnesol on Candida dubliniensis biofilm formation and fluconazole resistance. FEMS Yeast Res. 6, 1063-1073. 
Jacob, M. R., Hossain, C. F., Mohammed, K. A., Smillie, T. J., Clark, A. M., Walker, L. A., and Nagle, D. G. (2003). Reversal of fluconazole resistance in multidrug efflux-resistant fungi by the Dysidea arenaria sponge sterol 9alpha,11alpha-epoxycholest-7ene-3beta,5alpha,6alpha,19-tetrol 6-acetate. J. Nat. Prod. 66, 1618-1622.

Johann, S., Sa, N. P., Lima, L. A., Cisalpino, P. S., Cota, B. B., Alves, T. M., Siqueira, E. P., and Zani, C. L. (2010). Antifungal activity of schinol and a new biphenyl compound isolated from Schinus terebinthifolius against the pathogenic fungus Paracoccidioides brasiliensis. Ann. Clin. Microbiol. Antimicrob. 9, 30.

Kalemba, D., and Kunicka, A. (2003). Antibacterial and antifungal properties of essential oils. Curr. Med. Chem. 10, 813-829.

Kanafani, Z. A., and Perfect, J. R. (2008). Antimicrobial resistance: resistance to antifungal agents: mechanisms and clinical impact. Clin. Infect. Dis. 46, 120-128.

Kanetis, L., Forster, H., Jones, C. A., Borkovich, K. A., and Adaskaveg, J. E. (2008). Characterization of genetic and biochemical mechanisms of fludioxonil and pyrimethanil resistance in field isolates of Penicillium digitatum. Phytopathology 98, 205-214.

Kim, J., Campbell, B., Mahoney, N., Chan, K., Molyneux, R., and May, G. (2008a). Chemosensitization prevents tolerance of Aspergillus fumigatus to antimycotic drugs. Biochem. Biophys. Res. Commun. 372, 266-271.

Kim, J. H., Mahoney, N., Chan, K. L., Molyneux, R. J., May, G. S., and Campbell, B. C. (2008b). Chemosensitization of fungal pathogens to antimicrobial agents using benzo analogs. FEMS Microbiol. Lett. 281, 64-72.

Kim, J. H., Yu, J., Mahoney, N., Chan, K. L., Molyneux, R. J., Varga, J., Bhatnagar, D., Cleveland, T. E., Nierman, W. C., and Campbell, B. C. (2008c). Elucidation of the functional genomics of antioxidant-based inhibition of aflatoxin biosynthesis. Int. J. Food Microbiol. 122, 49-60.

Kim, J. H., Campbell, B. C., Mahoney, N., Chan, K. L., and Molyneux, R. J. (2011). Chemosensitization of aflatoxigenic fungi to antimycin A and strobilurin using salicylaldehyde, a volatile natural compound targeting cellular antioxidation system. Mycopathologia 171, 291-298.

Kim, J. H., Campbell, B. C., Mahoney, N., Chan, K. L., Molyneux, R. J., and
Balajee, A. (2010a). Augmenting the activity of antifungal agents against aspergilli using structural analogues of benzoic acid as chemosensitizing agents. Fungal Biol. 114, 817-824.

Kim, J. H., Campbell, B. C., Mahoney, N., Chan, K. L., Molyneux, R. J., and Xiao, C. L. (2010b). Use of chemosensitization to overcome fludioxonil resistance in Penicillium expansum. Lett. Appl. Microbiol. 51, 177-183.

Kim, J. H., Campbell, B. C., Mahoney, N., Chan, K. L., Molyneux, R. J., and May, G. S. (2007a). Enhanced activity of strobilurin and fludioxonil by using berberine and phenolic compounds to target fungal antioxidative stress response. Lett. Appl. Microbiol. 45, 134-141.

Kim, J. H., Campbell, B. C., Mahoney, N., Chan, K. L., Molyneux, R. J., and May, G. S. (2007b). Enhancement of fludioxonil fungicidal activity by disrupting cellular glutathione homeostasis with 2,5-dihydroxybenzoic acid. FEMS Microbiol. Lett. 270, 284-290.

Kim, J. H., Campbell, B. C., Yu, J., Mahoney, N., Chan, K. L., Molyneux, R. J., Bhatnagar, D., and Cleveland, T. E. (2005). Examination of fungal stress response genes using Saccharomyces cerevisiae as a model system: targeting genes affecting aflatoxin biosynthesis by Aspergillus flavus link. Appl. Microbiol. Biotechnol. 67, 807-815.

Krämer, W., and Schirmer, U. (eds). (2008). Modern Crop Protection Compounds. Weinheim: Wiley-VCH Verlag $\mathrm{GmbH}$.

Kubo, I., and Himejima, M. (1991). Anethole, a synergist of polygodial against filamentous microorganisms. J. Agric. Food Chem. 39, 2290-2292.

Kubo, I., Xiao, P., and Fujita, K. (2001). Antifungal activity of octyl gallate: structural criteria and mode of action. Bioorg. Med. Chem. Lett. 11, 347-350.

LaFayette, S. L., Collins, C., Zaas, A. K., Schell, W. A., Betancourt-Quiroz, M., Gunatilaka, A. A., Perfect, J. R., and Cowen, L. E. (2010). PKC signaling regulates drug resistance of the fungal pathogen Candida albicans via circuitry comprised of $\mathrm{Mkcl}$, calcineurin, and Hsp90. PLoS Pathog. 6, e1001069. doi:1001010.1001371/journal.ppat.1001069

Lee, S. H., and Kim, C. J. (1999). Selective combination effect of anethole to antifungal activities of miconazole and amphotericin B. Yakhakhoe Chi 43, 228-232.
Lei, G., Dan, H., Jinhua, L., Wei, Y., Song, G., and Li, W. (2011). Berberine and itraconazole are not synergistic in vitro against Aspergillus fumigatus isolated from clinical patients. Molecules 16, 9218-9233.

Levetin, E., and McMahon, K. (2003). Plants and Society. New York: McGraw-Hill.

Li, X. C., Jacob, M. R., Ding, Y., Agarwal, A. K., Smillie, T. J., Khan, S. I., Nagle, D. G., Ferreira, D., and Clark, A. M. (2006). Capisterones A and $\mathrm{B}$, which enhance fluconazole activity in Saccharomyces cerevisiae, from the marine green alga Penicillus capitatus. J. Nat. Prod. 69, 542-546.

Loeffler, J., and Stevens, D. A. (2003). Antifungal drug resistance. Clin. Infect. Dis. 36, S31-S41.

Low, C. Y., and Rotstein, C. (2011). Emerging fungal infections in immunocompromised patients. F1000 Med. Rep. 3, 14

Maertens, J. A. (2004). History of the development of azole derivatives. Clin. Microbiol. Infect. 10(Suppl. 1), 1-10.

Mahboubi, M., and Ghazian Bidgoli, F. (2010). In vitro synergistic efficacy of combination of amphotericin B with Myrtus communis essential oil against clinical isolates of Candida albicans. Phytomedicine 17,771-774.

Mahoney, N., and Molyneux, R. J. (2004). Phytochemical inhibition of aflatoxigenicity in Aspergillus flavus by constituents of walnut (Juglans regia). J. Agric. Food Chem. 52, 1882-1889.

Martin, D. S., and Jones, C. P. (1940). Further studies on the practical classification of the Monilias. J. Bacteriol. 39, 609-630.

Martins, C. V., da Silva, D. L., Neres, A. T., Magalhaes, T. F., Watanabe, G. A., Modolo, L. V., Sabino, A. A., de Fatima, A., and de Resende, M. A. (2009). Curcumin as a promising antifungal of clinical interest. $J$. Antimicrob. Chemother. 63, 337-339.

Messer, S. A., Moet, G. J., Kirby, J. T., and Jones, R. N. (2009). Activity of contemporary antifungal agents, including the novel echinocandin anidulafungin, tested against Candida spp., Cryptococcus spp., and Aspergillus spp.: Report from the SENTRY Antimicrobial Surveillance Program (2006 to 2007). J. Clin. Microbiol. 47, 1942-1946.

Mizuno, K., Zhiyentayev, T., Huang, L., Khalil, S., Nasim, F., Tegos, G. P., Gali, H., Jahnke, A., Wharton, T., and Hamblin, M. R. (2011). Antimicrobial photodynamic therapy with functionalized fullerenes: quantitative structure- activity relationships. J. Nanomed. Nanotechnol. 2, 1-9.

Morton, V., and Staub, T. (2008). A short history of fungicides. doi:10.1094/ APSnetFeature-2008-0308. [Online, APSnet Features].

Navarro-Martinez, M. D., GarciaCanovas, F., and Rodriguez-Lopez, J. N. (2006). Tea polyphenol epigallocatechin-3-gallate inhibits ergosterol synthesis by disturbing folic acid metabolism in Candida albicans. J. Antimicrob. Chemother. 57, 1083-1092.

Niimi, M., Niimi, K., Takano, Y., Holmes, A. R., Fischer, F. J., Uehara, Y., and Cannon, R. D. (2004). Regulated overexpression of CDR1 in Candida albicans confers multidrug resistance. J. Antimicrob. Chemother. 54, 999-1006.

Nucci, M., and Perfect, J. R. (2008). When primary antifungal therapy fails. Clin. Infect. Dis. 46, 1426-1433.

Odds, F. C. (2003a). Antifungal agents: their diversity and increasing sophistication. Mycologist 17, 51-55.

Odds, F. C. (2003b). Synergy, antagonism, and what the chequerboard puts between them. J. Antimicrob. Chemother. 52, 1.

Ogita, A., Fujita, K., Taniguchi, M., and Tanaka, T. (2006). Enhancement of the fungicidal activity of amphotericin B by allicin, an allyl-sulfur compound from garlic, against the yeast Saccharomyces cerevisiae as a model system. Planta Med. 72, 1247-1250.

Ogita, A., Matsumoto, K., Fujita, K., Usuki, Y., Hatanaka, Y., and Tanaka, T. (2007). Synergistic fungicidal activities of amphotericin B and $\mathrm{N}$-methyl- $\mathrm{N}^{\prime \prime}$-dodecylguanidine: a constituent of polyol macrolide antibiotic niphimycin. J. Antibiot. 60, 27-35.

Ogita, A., Yutani, M., Fujita, K., and Tanaka, T. (2010). Dependence of vacuole disruption and independence of potassium ion efflux in fungicidal activity induced by combination of amphotericin B and allicin against Saccharomyces cerevisiae. J. Antibiot. 63, 689-692.

Oh, K. B., Miyazawa, H., Naito, T., and Matsuoka, H. (2001). Purification and characterization of an autoregulatory substance capable of regulating the morphological transition in Candida albicans. Proc. Natl. Acad. Sci. U.S.A. 98, 4664-4668.

Okubo, S., Toda, M., Hara, Y., and Shimamura, T. (1991). Antifungal and fungicidal activities of tea extract and catechin against Trichophyton. Nippon Saikingaku Zasshi 46, 509-514. 
Onishi, J., Meinz, M., Thompson, J., Curotto, J., Dreikorn, S., Rosenbach, M., Douglas, C., Abruzzo, G., Flattery, A., Kong, L., Cabello, A., Vicente, F., Pelaez, F., Diez, M. T., Martin, I., Bills, G., Giacobbe, R., Dombrowski, A., Schwartz, R., Morris, S., Harris, G., Tsipouras, A., Wilson, K., and Kurtz, M. B. (2000). Discovery of novel antifungal $(1,3)$ beta-D-glucan synthase inhibitors. Antimicrob. Agents Chemother. 44, 368-377.

O'Shaughnessy, E. M., Meletiadis, J., Stergiopoulou, T., Demchok, J. P., and Walsh, T. J. (2006). Antifungal interactions within the triple combination of amphotericin B, caspofungin and voriconazole against Aspergillus species. J. Antimicrob. Chemother. 58, 1168-1176.

Panda, D., Rathinasamy, K., Santra, M. K., and Wilson, L. (2005). Kinetic suppression of microtubule dynamic instability by griseofulvin: implications for its possible use in the treatment of cancer. Proc. Natl. Acad. Sci. U.S.A. 102, 9878-9883.

Papon, N., Noel, T., Florent, M., GibotLeclerc, S., Jean, D., Chastin, C., Villard, J., and Chapeland-Leclerc, F. (2007). Molecular mechanism of flucytosine resistance in Candida lusitaniae: contribution of the FCY2, FCY1, and FUR1 genes to 5-fluorouracil and fluconazole cross-resistance. Antimicrob. Agents Chemother. 51, 369-371.

Park, B. J., Park, J.-C., Taguchi, H., Fukushima, K., Hyon, S.-H., and Takatori, K. (2006). Antifungal susceptibility of epigallocatechin 3-Ogallate (EGCg) on clinical isolates of pathogenic yeasts. Biochem. Biophys. Res. Commun. 347, 401-405.

Park, B. J., Taguchi, H., Kamei, K., Matsuzawa, T., Hyon, S. H., and Park, J. C. (2011). In vitro antifungal activity of epigallocatechin 3$\mathrm{O}$-gallate against clinical isolates of dermatophytes. Yonsei Med. J. 52, 535-538.

Park, B. J., Wannemuehler, K. A., Marston, B. J., Govender, N., Pappas, P. G., and Chiller, T. M. (2009). Estimation of the current global burden of cryptococcal meningitis among persons living with HIV/AIDS. AIDS 23, 525-530.

Pfaller, M., Boyken, L., Hollis, R., Kroeger, J., Messer, S., Tendolkar, S., and Diekema, D. (2011a). Comparison of the broth microdilution methods of the European Committee on Antimicrobial Susceptibility Testing and the Clinical and Laboratory Standards Institute for testing itraconazole, posaconazole, and voriconazole against Aspergillus isolates. J. Clin. Microbiol. 49, 1110-1112.

Pfaller, M. A., Castanheira, M., Diekema, D. J., Messer, S. A., and Jones, R. N. (2011b). Wild-type MIC distributions and epidemiologic cutoff values for fluconazole, posaconazole, and voriconazole when testing Cryptococcus neoformans as determined by the CLSI broth microdilution method. Diagn. Microbiol. Infect. Dis. 71, 252-259.

Pfaller, M. A., Espinel-Ingroff, A., Boyken, L., Hollis, R. J., Kroeger, J., Messer, S. A., Tendolkar, S., and Diekema, D. J. (2011c). Comparison of the broth microdilution (BMD) method of the European Committee on Antimicrobial Susceptibility Testing with the 24-hour CLSI BMD method for testing susceptibility of Candida species to fluconazole, posaconazole, and voriconazole by use of epidemiological cutoff values. J. Clin. Microbiol. 49, 845-850.

Pfaller, M. A., Diekema, D. J., Rinaldi, M. G., Barnes, R., Hu, B., Veselov, A. V., Tiraboschi, N., Nagy, E., and Gibbs, D. L. (2005). Results from the ARTEMIS DISK Global Antifungal Surveillance Study: a 6.5-year analysis of susceptibilities of Candida and other yeast species to fluconazole and voriconazole by standardized disk diffusion testing. J. Clin. Microbiol. 43, 5848-5859.

Phillips McDougall. (2006). Phillips McDougall Agriservice Report. Scotland: Pathhead.

Pinto, E., Pina-Vaz, C., Salgueiro, L., Goncalves, M. J., Costa-de-Oliveira, S., Cavaleiro, C., Palmeira, A., Rodrigues, A., and Martinez-deOliveira, J. (2006). Antifungal activity of the essential oil of Thymus pulegioides on Candida, Aspergillus and dermatophyte species. J. Med. Microbiol. 55, 1367-1373.

Pinto, E., Vale-Silva, L., Cavaleiro, C., and Salgueiro, L. (2009). Antifungal activity of the clove essential oil from Syzygium aromaticum on Candida, Aspergillus and dermatophyte species. J. Med. Microbiol. 58, 1454-1462.

Pyun, M.-S., and Shin, S. (2006). Antifungal effects of the volatile oils from Allium plants against Trichophyton species and synergism of the oils with ketoconazole. Phytomedicine 13, 394-400.

Quan, H., Cao, Y. Y., Xu, Z., Zhao, J. X., Gao, P. H., Qin, X. F., and Jiang, Y. Y. (2006). Potent in vitro synergism of fluconazole and berberine chloride against clinical isolates of Candida albicans resistant to fluconazole. Antimicrob. Agents Chemother. 50, 1096-1099.

Ramage, G., Saville, S. P., Wickes, B. L., and Lopez-Ribot, J. L. (2002). Inhibition of Candida albicans biofilm formation by farnesol, a quorumsensing molecule. Appl. Environ. Microbiol. 68, 5459-5463.

Rao, A., Zhang, Y., Muend, S., and Rao, R. (2010). Mechanism of antifungal activity of terpenoid phenols resembles calcium stress and inhibition of the TOR pathway. Antimicrob. Agents Chemother. 54, 5062-5069.

Roling, E. E., Klepser, M. E., Wasson, A., Lewis, R. E., Ernst, E. J., and Pfaller, M. A. (2002). Antifungal activities of fluconazole, caspofungin (MK0991), and anidulafungin (LY 303366) alone and in combination against Candida spp. and Cryptococcus neoformans via time-kill methods. Diagn. Microbiol. Infect. Dis. 43, 13-17.

Rosato, A., Vitali, C., Piarulli, M., Mazzotta, M., Argentieri, M. P., and Mallamaci, R. (2009). In vitro synergic efficacy of the combination of Nystatin with the essential oils of Origanum vulgare and Pelargonium graveolens against some Candida species. Phytomedicine 16, 972-975.

Russell, P. E. (2005). A century of fungicide evolution. J. Agric. Sci. 143, 11-25.

Shabbits, J. A., Hu, Y., and Mayer, L. D. (2003). Tumor chemosensitization strategies based on apoptosis manipulations. Mol. Cancer Ther. 2 , 805-813.

Sharma, M., Manoharlal, R., Negi, A. S., and Prasad, R. (2010a). Synergistic anticandidal activity of pure polyphenol curcumin I in combination with azoles and polyenes generates reactive oxygen species leading to apoptosis. FEMS Yeast Res. 10, 570-578.

Sharma, M., Manoharlal, R., Puri, N., and Prasad, R. (2010b). Antifungal curcumin induces reactive oxygen species and triggers an early apoptosis but prevents hyphae development by targeting the global repressor TUP1 in Candida albicans. Biosci. Rep. 30, 391-404.

Shen, J., Davis, L. E., Wallace, J. M., Cai, Y., and Lawson, L. D. (1996). Enhanced diallyl trisulfide has in vitro synergy with amphotericin B against Cryptococcus neoformans. Planta Med. 62, 415-418.

Shen, Y. Z., Lu, H. Z., and Zhang, Y. X. (2010). Molecular mechanisms of fluconazole resistance in clinical isolates of Candida glabrata. Zhonghua Nei Ke Za Zhi 49, 245-249.
Shimokawa, O., and Nakayama, H. (1992). Increased sensitivity of Candida albicans cells accumulating 14 alpha-methylated sterols to active oxygen: possible relevance to in vivo efficacies of azole antifungal agents. Antimicrob. Agents Chemother. 36, 1626-1629.

Shin, S. (2003). Anti-Aspergillus activities of plant essential oils and their combination effects with ketoconazole or amphotericin B. Arch. Pharm. Res. 26, 389-393.

Shin, S., and Kang, C. A. (2003). Antifungal activity of the essential oil of Agastache rugosa Kuntze and its synergism with ketoconazole. Lett. Appl. Microbiol. 36, 111-115.

Shin, S., and Pyun, M. S. (2004). Anti-Candida effects of estragole in combination with ketoconazole or amphotericin B. Phytother. Res. 18, 827-830.

Shirtliff, M. E., Krom, B. P., Meijering, R. A., Peters, B. M., Zhu, J., Scheper, M. A., Harris, M. L., and Jabra-Rizk, M. A. (2009). Farnesol-induced apoptosis in Candida albicans. Antimicrob. Agents Chemother. 53, 2392-2401.

Shreaz, S., Bhatia, R., Khan, N., Ahmad, S. I., Muralidhar, S., Basir, S. F., Manzoor, N., and Khan, L. A. (2011a). Interesting anticandidal effects of anisic aldehydes on growth and proton-pumpingATPase-targeted activity. Microb. Pathog. 51, 277-284.

Shreaz, S., Maurya, I. K., Bhatia, R. Khan, N., Muralidhar, S., Manzoor, N., and Khan, L. A. (2011b). Influences of cinnamic aldehydes on plasma membrane $\mathrm{H}+$ ATPase activity and ultrastructure of Candida. J. Med. Microbiol. (in press). doi:10.1099/jmm.0.036145-0

Singh, B. N., and Vaughan Williams, E. M. (1970). The effect of amiodarone, a new anti-anginal drug, on cardiac muscle. Br. J. Pharmacol. 39, 657-667.

Singh, R. P., Hodson, D. P., HuertaEspino, J., Jin, Y., Bhavani, S., Njau, P., Herrera-Foessel, S., Singh, P. K., Singh, S., and Govindan, V. (2011). The emergence of Ug99 races of the stem rust fungus is a threat to world wheat production. Annu. Rev. Phytopathol. 49, 465-481.

Singh, R. P., Hodson, D. P., HuertaEspino, J., Jin, Y., Njau, P., Wanyera, R., Herrera-Foessel, S. A., and Ward, R. W. (2008). "Will stem rust destroy the world's wheat crop?" in Advances in Agronomy, ed. L. S. Donald (Waltham, MA: Academic Press), 271-309.

Singh, S. D., Robbins, N., Zaas, A. K., Schell, W. A., Perfect, J. 
R., and Cowen, L. E. (2009). Hsp90 governs echinocandin resistance in the pathogenic yeast Candida albicans via calcineurin. PLoS Pathog. 5, e1000532. doi:1000510.1001371/journal.ppat. 1000532

Snelders, E., Huis In 't Veld, R. A., Rijs, A. J., Kema, G. H., Melchers, W. J., and Verweij, P. E. (2009). Possible environmental origin of resistance of Aspergillus fumigatus to medical triazoles. Appl. Environ. Microbiol. 75, 4053-4057.

Snell, S. B., Foster, T. H., and Haidaris, C. G. (2011). Miconazole induces fungistasis and increases killing of Candida albicans subjected to photodynamic therapy. Photochem. Photobiol. doi:10.1111/j.1751-1097.2011.01039.x [Epub ahead of print].

Steinbach, W. J., Juvvadi, P. R., Fortwendel, J. R., and Rogg, L. E. (2011). Newer combination antifungal therapies for invasive aspergillosis. Med. Mycol. 49, S77-S81.

Strange, R. N., and Scott, P. R. (2005). Plant disease: a threat to global food security. Annu. Rev. Phytopathol. 43, 83-116.

Strippoli, V., Dauria, F. D., Tecca, M., Callari, A., and Simonetti, G. (2000). Propyl gallate increases in vitro antifungal imidazole activity against Candida albicans. Int. J. Antimicrob. Agents 16, 73-76.

Sun, L., Sun, S., Cheng, A., Wu, X., Zhang, Y., and Lou, H. (2009a). In vitro activities of retigeric acid $\mathrm{B}$ alone and in combination with azole antifungal agents against Candida albicans. Antimicrob. Agents Chemother. 53, 1586-1591.

Sun, L. M., Cheng, A. X., Wu, X. Z., Zhang, H. J., and Lou, H. X. (2009b). Synergistic mechanisms of retigeric acid $\mathrm{B}$ and azoles against Candida albicans. J. Appl. Microbiol. 108, 341-348.
Suresh, B., Sriram, S., Dhanaraj, S. A., Elango, K., and Chinnaswamy, K. (1997). Anticandidal activity of Santolina chamaecyparissus volatile oil. J. Ethnopharmacol. 55, 151-159.

Thompson, G. R. III, Cadena, J., and Patterson, T. F. (2009). Overview of antifungal agents. Clin. Chest Med. 30, 203-215.

Tseng, H.-K., and Perfect, J. R. (2011). Strategies to manage antifungal drug resistance. Expert Opin. Pharmacother. 12, 241-256.

Vermes, A., Guchelaar, H. J., and Dankert, J. (2000). Flucytosine: a review of its pharmacology, clinical indications, pharmacokinetics, toxicity and drug interactions. J. Antimicrob. Chemother. 46, 171-179.

Wagner, H., and Ulrich-Merzenich, G. (2009). Synergy research: approaching a new generation of phytopharmaceuticals. Phytomedicine 16, 97-110.

Walsh, T. J., Anaissie, E. J., Denning, D. W., Herbrecht, R., Kontoyiannis, D. P., Marr, K. A., Morrison, V. A., Segal, B. H., Steinbach, W. J., Stevens, D. A., van Burik, J.-A., Wingard, J. R., and Patterson, T. F. (2008). Treatment of aspergillosis: clinical practice guidelines of the infectious diseases society of America. Clin. Infect. Dis. 46, 327-360.

Wink, M. (2008). Evolutionary advantage and molecular modes of action of multi-component mixtures used in phytomedicine. Curr. Drug Metab. 9, 996-1009.

Xu, Y., Pang, G. R., Lu, X. F., Chen, Z. J., Sun, S. T., and Song, J. Z. (2006). The effect of propyl gallate on the activity of various antifungal drugs against filamentous fungi in vitro. Zhonghua Yan Ke Za Zhi 42, 309-312.

Xu, Y., Wang, Y., Yan, L., Liang, R. M., Dai, B. D., Tang, R. J., Gao, P. H., and Jiang, Y. Y. (2009). Proteomic analysis reveals a synergistic mechanism of fluconazole and berberine against fluconazole-resistant Candida albicans: endogenous ROS augmentation. J. Proteome Res. 8, 5296-5304.

Yen, T. B., and Chang, S. T. (2008). Synergistic effects of cinnamaldehyde in combination with eugenol against wood decay fungi. Bioresour. Technol. 99, 232-236.

Yu, J., Ronning, C. M., Wilkinson, J. R., Campbell, B. C., Payne, G. A., Bhatnagar, D., Cleveland, T. E., and Nierman, W. C. (2007). Gene profiling for studying the mechanism of aflatoxin biosynthesis in Aspergillus flavus and A. parasiticus. Food Addit. Contam. 24, 1035-1042.

Yu, L., Guo, N., Meng, R., Liu, B., Tang, X., Jin, J., Cui, Y., and Deng, X. (2010). Allicin-induced global gene expression profile of Saccharomyces cerevisiae. Appl. Microbiol. Biotechnol. 88, 219-229.

Yu, L., Ling, G., Deng, X., Jin, J., Jin, Q., and Guo, N. (2011). In vitro interaction between fluconazole and triclosan against clinical isolates of fluconazole-resistant Candida albicans determined by different methods. Antimicrob. Agents Chemother. 55, 3609-3612.

Yu, L. H., Wei, X., Ma, M., Chen, X. J., and Xu, S. B. (2012). Possible inhibitory molecular mechanism of farnesol on the development of fluconazole resistance in Candida albicans biofilm. Antimicrob. Agents Chemother. 56, 770-775.

Yutani, M., Hashimoto, Y., Ogita, A. Kubo, I., Tanaka, T., and Fujita, K. (2011a). Morphological changes of the filamentous fungus Mucor mucedo and inhibition of chitin synthase activity induced by anethole. Phytother. Res. 25, 1707-1713.

Yutani, M., Ogita, A., Usuki, Y., Fujita, K., and Tanaka, T. (2011b). Enhancement effect of N-methyl$\mathrm{N}^{\prime}$-dodecylguanidine on the vacuole-targeting fungicidal activity of amphotericin B against the pathogenic fungus Candida albicans. J. Antibiot. 64, 469-474.

Zarember, K. A., Cruz, A. R., Huang, C. Y., and Gallin, J. I. (2009). Antifungal activities of natural and synthetic iron chelators alone and in combination with azole and polyene antibiotics against Aspergillus fumigatus. Antimicrob. Agents Chemother. 53, 2654-2656.

Zore, G. B., Thakre, A. D., Jadhav, S., and Karuppayil,S.M.(2011). Terpenoids inhibit Candida albicans growth by affecting membrane integrity and arrest of cell cycle. Phytomedicine 18, 1181-1190.

Zuzarte, M., Goncalves, M. J., Cavaleiro, C., Canhoto, J., Vale-Silva, L., Silva, M. J., Pinto, E., and Salgueiro, L. (2011). Chemical composition and antifungal activity of the essential oils of Lavandula viridis L'Her. J. Med. Microbiol. 60, 612-618.

Conflict of Interest Statement: The authors declare that the research was conducted in the absence of any commercial or financial relationships that could be construed as a potential conflict of interest.

Received: 17 December 2011; accepted: 15 February 2012; published online: 29 February 2012.

Citation: Campbell BC, Chan KL and Kim JH (2012) Chemosensitization as a means to augment commercial antifungal agents. Front. Microbio. 3:79. doi: 10.3389/fmicb.2012.00079

This article was submitted to Frontiers in Fungi and Their Interactions, a specialty of Frontiers in Microbiology.

Copyright (C) 2012 Campbell, Chan and Kim. This is an open-access article distributed under the terms of the Creative Commons Attribution Non Commercial License, which permits noncommercial use, distribution, and reproduction in other forums, provided the original authors and source are credited. 